\title{
SimPlified HYMOD NON-Linear Simulations of A Full-SCAlE Multistory RetrofitTed RC STRUCTURE THAT UNDERgoes MULTIPLE CyClic ExCITATIONS - AN INFILL RC WALL RETROFITTING STUDY
}

\author{
George Markou*1, Christos Mourlas $^{2 a}$, Hussein Bark ${ }^{3 b}$ and Manolis Papadrakakis ${ }^{2 c}$ \\ ${ }^{1}$ Department of Civil Engineering, University of Pretoria, Republic of South Africa \\ ${ }^{2}$ Department of Civil Engineering, National Technical University of Athens, Greece \\ ${ }^{3}$ Department of Civil Engineering, Technical University of Munich, Germany
}

\begin{abstract}
Keywords: Hybrid Finite Elements, Cyclic Loading, Retrofitting Infill Walls, CFRP Jacketing, LargeScale Modeling.
\end{abstract}

\begin{abstract}
Having the ability to assess the earthquake resistance of retrofitted reinforced concrete (RC) structures through accurate and objective nonlinear cyclic analysis is of great importance for both scientists and professional Civil Engineers. Full-scale RC structure simulations under ultimate limit state cyclic loading conditions through the use of 3D detail modeling techniques, is currently one of the most challenging modeling tasks that any research or commercial software can undertake. The excessive computational demand and the numerical instabilities that occur when dealing with this type of cyclic nonlinear numerical analysis, make this modeling approach impractical. The simplified hybrid modeling (HYMOD) approach is adopted in this work, which overcomes the above numerical limitations and it is used herein to illustrate the capabilities of the method in capturing the experimental results of a full-scale 4-storey RC building that was retrofitted with RC infill walls and carbon fiber reinforced polymer jacketing. This work has the aim to investigate the importance of numerically accounting for the damage that has developed at the concrete and steel domains during the analysis of problems that foresee consecutive cyclic loading tests. Based on the numerical findings, it was concluded that the proposed modeling approach was able to accurately capture the experimental data and predict the capacity degradation of the building specimen. Furthermore, the proposed method was used to numerically investigate different retrofitting configurations that foresaw the use of infill $\mathrm{RC}$ walls. The numerical experiments performed in this work demonstrate that the proposed modeling approach provides with the ability to study the cyclic mechanical behavior of full-scale RC structures under ultimate limit state conditions, thus paves the way in performing additional parametric investigations in determining the optimum retrofitting design of RC structures by using different types of interventions.
\end{abstract}

\section{Introduction}

Based on the discussion presented in Markou et al. (2017), when dealing with the modeling of reinforced concrete (RC) structures under extreme cyclic conditions, many numerical challenges arise given the complexity of the mechanical behavior of the concrete material. Many researchers attempted to develop numerous simplified numerical models that would provide with the ability to simulate the nonlinear mechanical behavior of concrete structures in an accurate and computationally efficient manner. Nonetheless, engaging 1D and 2D numerical models has a main challenge that relates to the accuracy limitations of these type of models. Therefore, researchers turned towards more detailed 3D approaches (Hartl (2002), Lykidis and Spiliopoulos (2008), Červenka and Papanikolaou (2008), Papanikolaou and Kappos (2009), Markou and Papadrakakis (2013), Bark et al. (2016) and Mourlas et al. 2017), in an attempt to develop more accurate numerical models that will be able to provide them with the necessary tools for predicting the mechanical response of any RC structural member in an objective manner.

One of the main numerical limitations when dealing with 3D detailed modeling through the use of solid elements, is the high computational demand that arises during nonlinear analysis that limited this

\footnotetext{
*Corresponding Author, Associate Professor, E-mail: george.markou@up.ac.za

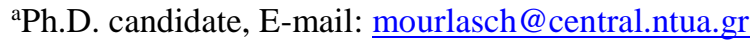

'Professor, E-mail: mpapadra@ central.ntua.gr
} 
research work (Hartl (2002), Lykidis and Spiliopoulos (2008), Červenka and Papanikolaou (2008), Papanikolaou and Kappos (2009), Markou and Papadrakakis (2013), Bark et al. (2016) and Mourlas et al. 2017), to study single RC structural members or relatively small structural configurations (i.e. 1span RC frames). When using the 3D detailed numerical approach, scientists are forced to study single structural members or joints in order to get results in an acceptable computational time. This modeling constraint is always accompanied by the problem that is known as "numerical instabilities", which immerses due to the numerically complicated nature of the cyclic mechanical response of concrete (mainly due to the opening and closing of cracks and the material's deterioration due to multiple loading cycles).

In order to overcome these computational limitations, several scientists proposed the use of hybrid models that foresee the combination of different in dimensionality finite elements that are used to discretize the frame of any structure. As it was presented by Markou et al. (2018), mixed element formulations and other hybrid techniques were proposed in several publications (Nazarov (1996), Nazarov (1999), Formaggia et al. (2001), Kozlov and Maz'ya (2001), Huang (2004), Urquiza et al. (2006), Blanco et al. (2007), Blanco et al. (2008), Mata et al. (2008), Bournival et al. 2010), where only one of them was actually dealing with the cyclic analysis of RC frames (Mata et al. 2008). In their study, Markou et al. (2017) used the HYMOD approach so as to develop the full-scale model of the 4-storey RC specimen that was experimentally studied in Martin et al. (2013). The physical experiment (Martin et al. 2013) foresaw three different cyclic loading tests that the RC specimen undergone in a serial manner, whereas only the first test was modeled in Markou et al. (2017) for validation purposes. This is considered to be the most recent research work that uses the HYMOD approach after the method was presented in Markou et al. (2018). Based on the research findings presented in Markou et al. (2017), Markou et al. (2018) proposed algorithm has set the foundations for full-scale RC structure simulations by presenting an integrated algorithm that uses 8-noded hexahedral finite elements that treat cracking through the smeared crack approach and model the reinforcement through the use of embedded rebar finite elements (rod or beam).

The proposed HYMOD algorithm (Markou and Papadrakakis 2015, Markou et al. 2017, Markou et al. 2018) is used in this work so as to model all three loading history tests imposed on the 4-storey RC building that was experimentally tested by Martin et al. (2013), in an attempt to demonstrate the HYMOD's numerical advantages when dealing with large-scale models and excessive nonlinearities that result into significant material degradations. It must be noted at this point that an attempt to simulate the 4-storey RC building was performed by Kyriakides et al. (2015), where 1D and 2D finite elements were used to develop the finite element models and analyze the specimen for the case of the $2^{\text {nd }}$ loading test. Based on their numerical models (Kyriakides et al. 2015), the CFRP jacketing was not included during the analyses, whereas the damage that occurred during the $1^{\text {st }}$ loading test was also not accounted for during the analysis of the $2^{\text {nd }}$ loading test. Furthermore, the actual uniaxial compressive strength of concrete reported in Martin et al. (2013) was $20 \mathrm{MPa}$ (C20/25) for a cylindrical specimen, while the uniaxial compressive strength used during the analysis in Kyriakides et al. (2015) was $33.8 \mathrm{MPa}$ and had a $3.6 \mathrm{MPa}\left(10.65 \% f_{c}\right)$ tensile strength, which deviates by $69 \%$ from the reported value. The Young modulus of elasticity for concrete was set to $20 \mathrm{GPa}$, as it was reported in Kyriakides et al. (2015), which was also not equal to the $30 \mathrm{GPa}$ reported value found in Martin et al. (2013). The 2D developed model presented in Kyriakides et al. (2015), was used to simulate approximately a $70 \%$ of the $2^{\text {nd }}$ loading test, deriving numerical results that underestimated the maximum experimentally obtained capacity of the base-shear by more than $25 \%$. A more accurate prediction in terms of base shear capacity was obtained when a SAP2000 model was used, but in this case the hysteretic behavior of the numerically computed curve was not able to match the experimental data, while the CFRP jacketing was once again not accounted for nor the damage that occurred during the $1^{\text {st }}$ loading test.

This highlights the need of a more accurate and numerically robust modeling method, in order to be able to assess retrofitted structures by using full-scale numerical models that will account for the full spectrum of loading conditions and account for material degradation due to previous loading excitations. This is also of great importance when assessing existing RC buildings that have undergone an earthquake thus have previously developed damages at different parts of their framing system. 
One of the main objectives herein, is to demonstrate that the proposed modeling scheme is able to satisfy the above requirements without making simplification assumptions or significantly altering the material properties in comparison to the experimentally reported values. The adopted material constitutive models and the HYMOD approach that were used in this work are presented in sections 2 and 3, respectively, while the retrofitting types that were applied on the RC building (and numerically modeled in this research work) are presented in section 4. The computational efficiency, robustness and accuracy of the proposed algorithm are investigated and discussed in section 5. Furthermore, the ability in capturing the mechanical behavior of retrofitted RC structures is presented in this section as well, while the numerical ability of the developed algorithm in capturing the stiffness and capacity degradation of the building due to the concrete damage during the three loading tests is also demonstrated through an additional parametric investigation that will be presented in section 5.4. Finally, a modal analysis algorithm that is able to compute the eigenmodes and eigenfrequencies of HYMOD models is developed and applied herein in an attempt to further investigate different retrofitting configurations that are presented in section 5.5. This numerical investigation aims in the detail study of the retrofitting method that foresees the use of infill RC walls and its qualitative and quantitate effects in terms of shear capacity and energy dissipation enhancement. The numerical results of this numerical investigation are discussed in section 5.5.

\section{Material Modeling}

The HYMOD approach for cyclic modeling (Markou et al. 2018) considers two different types of finite element (FE) models for discretizing the frame of any building-like structure. Based on the proposed framework of Markou and Papadrakakis (2015), these element types are the isoparametric hexahedral element and the Natural Beam-Column Flexibility-Based (NBCFB) fiber element. The two elements have a numerical formulation that is based on 3- and 1-dimensional domains, respectively. Therefore, two concrete material constitutive models have to be considered in order to simulate any structure by using HYMOD meshes. When the NBCFB is used, the discretization foresees the division of each beam-column section into fibers that have the ability to account for nonlinearities through the bilinear model. This numerical model provides both efficiency and numerical stability. All the analyses performed in this research work foresaw a hardening modulus equal to zero.

The 3D concrete material model, which is incorporated into the 8-noded hexahedral element, is based on the proposed algorithm presented in Mourlas et al. (2017) and Markou et al. (2018), where the cyclic mechanical behavior of RC members is numerically investigated. The model is based on the concrete material model that was integrated with a new crack closure criterion, which induces numerical stability during the cyclic analysis (Mourlas et al. 2017). The smeared crack approach is used to simulate the crack openings in the case of the 3D detailed model, an approach that was presented by Rashid (1968) as an extension to the method proposed by Gonzalez-Vidosa et al. (1991). Smeared crack models take into consideration crack openings by modifying the stiffness matrices and stresses at the corresponding integration points (Fig. 1).
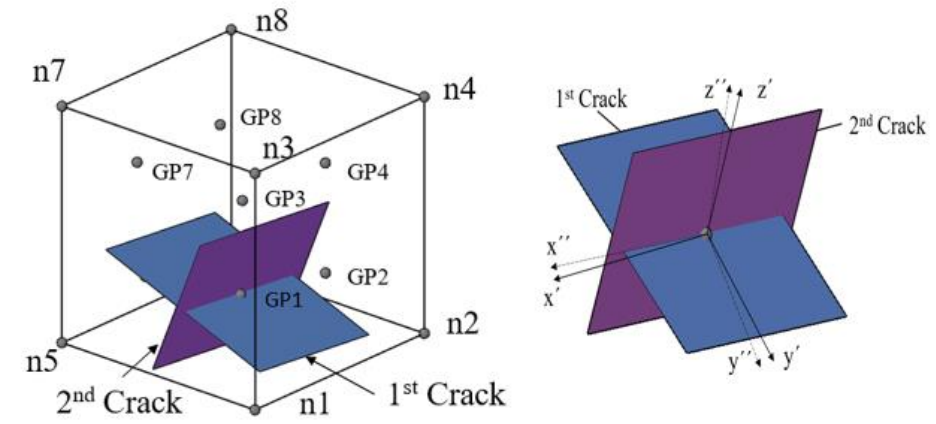

Fig. 1. Local axes for the case of two cracks at a specific Gauss point. (Markou et al. 2018)

The crack opening strategy during each load increment foresees the use of the unified total crack approach (UTCA) proposed by Lykidis and Spiliopoulos (2008), which foresees that the state of crack formation or closure is treated in a unified way within every Newton-Raphson internal iteration. The concrete material assumes that it loses all of its carrying capacity along the vertical direction of the 
crack, thus behaves in a brittle manner. The expression of the strength envelope of concrete is provided in Eq. 1 and it's based on the Willam and Warkne (1974) formulae.

$$
\tau_{0 u}=\frac{2 \tau_{0 c}\left(\tau_{0 c}^{2}-\tau_{0 e}^{2}\right) \cos \theta+\tau_{0 c}\left(2 \tau_{0 e}-\tau_{0 c}\right) \sqrt{4\left(\tau_{0 c}^{2}-\tau_{0 e}^{2}\right) \cos ^{2} \theta+5 \tau_{0 e}^{2}-4 \tau_{0 c}^{2} \tau_{0 e}^{2}}}{4\left(\tau_{0 c}^{2}-\tau_{0 e}^{2}\right) \cos ^{2} \theta+\left(2 \tau_{0 e}-\tau_{0 c}\right)^{2}}
$$

where the rotational variable $\theta$ defines the deviatoric stress orientation on the octahedral plane. The $\tau_{0 e}\left(\theta=0^{\circ}\right)$ and $\tau_{0 c}\left(\theta=60^{\circ}\right)$ correspond to the state of $\sigma_{1}=\sigma_{2}>\sigma_{3}$ (triaxial extension) and $\sigma_{1}>\sigma_{2}=\sigma_{3}$ (triaxial compression), respectively and are expressed analytically by experimental data.

The material modeling procedure also uses a flexible crack closing criterion introduced in Mourlas et al. (2017). This numerical criterion was found to play a significant role during the cyclic loading analysis for achieving a faster convergence ratio. According to the proposed criterion in Mourlas et al. (2017), the closure of cracks is expressed based on the following equation:

$$
\varepsilon_{i} \leq\left(b-\frac{n_{c r}-1}{n_{t o t}}\right) \varepsilon_{c r}
$$

where $\varepsilon_{i}$ is the current strain in the i-direction that is normal to the crack plane and $\varepsilon_{c r}$ is the strain that causes cracking formation. Parameter $b$ is the number of the imposed displacement branch of the load history, while $n_{c r}$ and $n_{t o t}$ are the numbers of increment that the crack is formed at and the total number of increments that an imposed displacement branch is divided into, respectively. More details on the cracks closure criterion can be found in Mourlas et al. (2017).

For the case of the embedded rebar elements found within the hexahedral mesh, the HYMOD algorithmic framework foresees the use of the Menegotto-Pinto (1973) model that takes into account the Bauschinger effect.

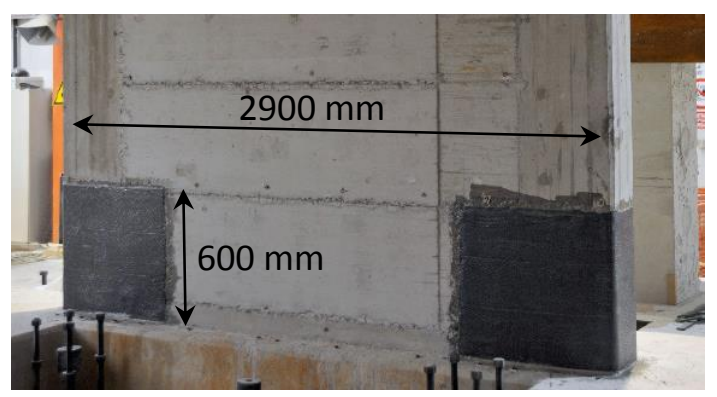

Fig. 2. Three-sided CFRP jacketing. (Martin et al. 2013)

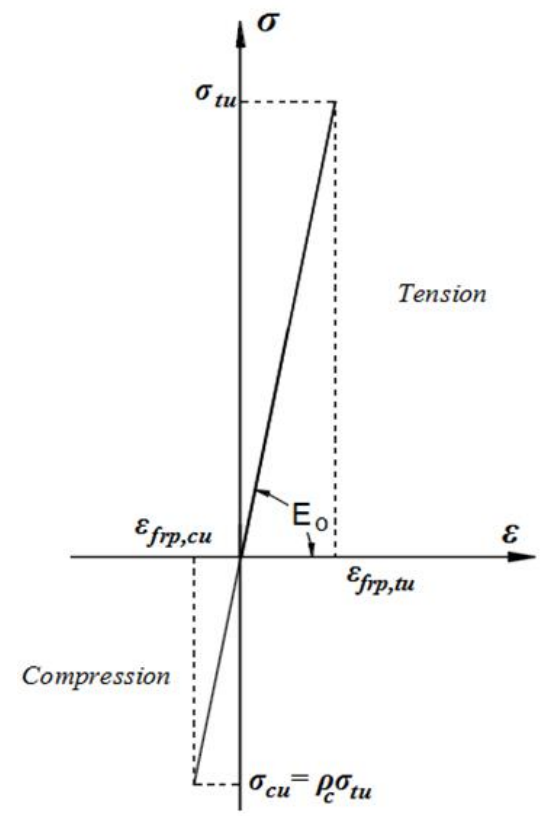

Fig. 3. Material model of the CFRP jacketing. (Markou and AlHamaydeh 2017)

The under study multi-storey RC structure was retrofitted through the use of a three-sided Carbon 
Fiber Reinforced Polymer (CFRP) jacket so as to confine the edges of the two walls at the ground floor level. This was done in an attempt to avoid a premature termination of the experiment due to a potential high concrete deterioration (Martin et al. 2013) at the wall edges. Fig. 2 shows the CFRP jacket $(600 \mathrm{~mm}$ in height) that was used to reinforce the wall edges according to the design of the experimental setup found in Martin et al. (2013).

In this research work, the CFRP jacketing was also discretized in detail (see section 5.1) by using hexahedral elements, where the material model used in simulating the stress-strain relationship for the CFRP jacketing, foresaw a linear behavior until complete failure for both tension and compression states, as illustrated in Fig. 3. When the ultimate stress level is reached within the CFRP material, the model foresees a complete loss of its capacity. The experimental results reported that the CFRP jackets did not exhibit any damages or failure at the material level. Therefore, the ultimate tensile strength was set to $1,000 \mathrm{MPa}$ and the Young Modulus of elasticity was set equal to $100 \mathrm{GPa}$. In addition to that, it was also assumed that the CFRP jacketing had full bonding with the concrete, which also complies with the experimental findings reported in Martin et al. (2013) (no CFRP-concrete detachment was reported).

\section{Hybrid Modeling Formulation - Kinematical Coupling of 1D and 3D Finite Elements}

The HYMOD approach was integrated with the concrete cyclic material model in Markou et al. (2018), whereas the coupling between the beams and hexahedral elements is achieved through kinematic constraints. The kinematic constraints are enforced at each hexahedral node, located at the interface between the beam and the solid elements, through the following relationships:

$$
\underset{(3 x 1)}{\boldsymbol{u}_{i}^{H E X A}}=\underset{(3 x 6)}{\boldsymbol{T}_{i m}} \cdot \underset{(6 \times 1)}{\boldsymbol{u}_{m}^{N B C F B},}
$$

with

$$
\underset{(3 x 6)}{\boldsymbol{T}_{i m}}=\left[\begin{array}{cccccc}
1 & 0 & 0 & 0 & z_{i}-z_{m} & y_{m}-y_{i} \\
0 & 1 & 0 & z_{m}-z_{i} & 0 & x_{i}-x_{m} \\
0 & 0 & 1 & y_{i}-y_{m} & x_{m}-x_{i} & 0
\end{array}\right]
$$

where $\boldsymbol{u}_{m}^{\text {NBCFB }}$ and $\boldsymbol{u}_{i}^{\text {HEXA }}$ are the displacement vectors of the beam-column FE node corresponding to 6 dofs and the hexahedral nodes ( 3 dofs per node) located at the interface, respectively. The subscript $i$ of the global coordinates $\mathrm{x}, \mathrm{y}$ and $\mathrm{z}$, refers to the hexahedral node ID which is located at the interface section $\Omega_{\mathrm{i}}^{1}$, while subscript $m$ refers to the beam-column elemental node ID that controls the displacements (master node) of the interface section $\boldsymbol{\Omega}_{i}^{1}$ (Fig. 4). The matrix $\boldsymbol{T}_{i m}$, which is used to connect the different dimensionality displacements, is computed from the compatibility conditions of beam-column and hexahedral nodal Cartesian coordinates.

If the hexahedral node is located at the interface of a beam-column and hexahedral elements, it should follow the body movements of $\operatorname{section} \Omega_{i}^{1}$, which are enforced by the beam-column element nodal translational and rotational displacements (Fig. 4). Therefore, the computation of the new position for any point on the interface section $\boldsymbol{\Omega}_{i}^{1}$ is obtained through a linear transformation which is expressed as follows:

$$
\underset{(24 x 1)}{\boldsymbol{U}^{\mathrm{HEXA}}}=\underset{(24 x 18)}{\boldsymbol{T}_{H}} \cdot \underset{(18 x 1)}{\boldsymbol{U}^{\text {hybrid }}}
$$

The transformation matrix $\boldsymbol{T}_{H}$ is computed by using the coordinates of the "slave" nodes (which are controlled by the kinematic constraints) and the $x_{m}, y_{m}, z_{m}$ coordinates of the corresponding "master" node. The transformation matrix $\boldsymbol{T}_{H}$ is used for obtaining the $18 \times 18$ transformed stiffness matrix of each hybrid hexahedral element, according to Eq. 8, while the nodal displacements of the "slave" nodes are computed according to Eq. 7.

$$
\underset{(18 \times 18)}{\boldsymbol{K}_{H}^{\mathrm{HEXA}}}=\underset{(18 \times 24)}{\boldsymbol{T}_{H}^{T}} \cdot \underset{(24 \times 24)}{\boldsymbol{K}^{\text {HEXA }}} \underset{(24 \times 18)}{\boldsymbol{T}_{H}}
$$

The calculation of the internal forces of the transformed hexahedral elements is performed as 
follows:

$$
\underset{(18 x 1)}{\boldsymbol{F}_{H}}=\underset{(18 x 24)}{\boldsymbol{T}_{H}^{T}} \cdot \boldsymbol{F}_{(24 x 1)}^{\mathrm{HEXA}}
$$

where $\boldsymbol{F}_{H}$ is the internal force vector of the transformed hexahedral element. More details on the kinematic constraints can be found in Markou and Papadrakakis (2015).

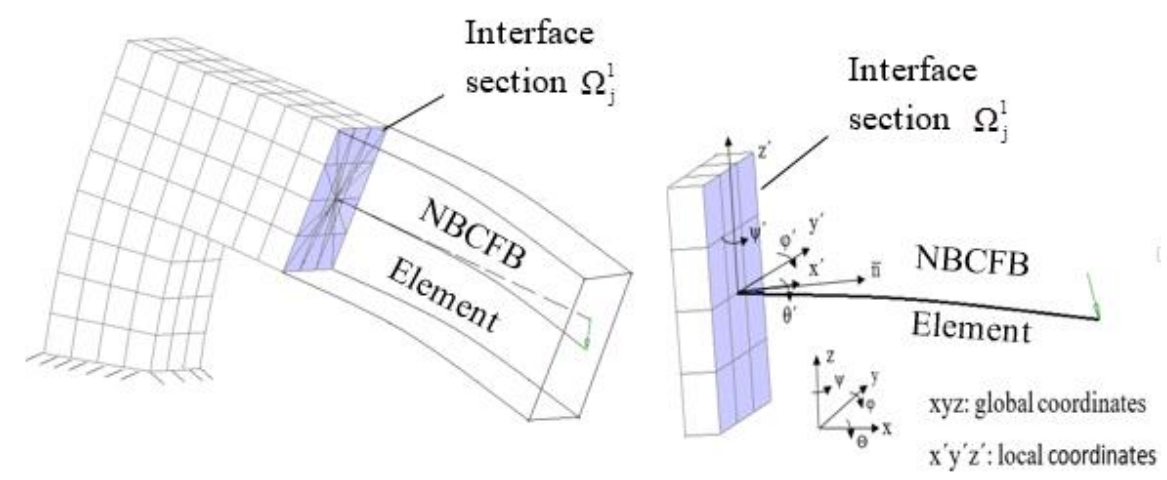

Fig. 4. Kinematic constraints imposed by the 1D structural member on the interface section $\boldsymbol{\Omega}_{i}^{1}$. (Markou et al. 2018)

\section{Experimental Data}

A full-scale 4-storey RC building was studied in the SERFIN project (Martin et al. 2013), which was the first experimental attempt that studied a full-scale building specimen that was constructed to investigate the retrofitting of buildings through the use of RC infill walls and CFRP jacketing. As it was reported in Martin et al. (2013), the 4-storey RC building was tested with the pseudo-dynamic method (PSD) and had two 4-storey parallel frames connected through a continues slab of $15 \mathrm{~cm}$ thickness and four out-of-plane central beams that connected the two frames between them (Figs. 56). Each frame consisted of 3 bays with an $8.9 \mathrm{~m}$ of total span, with the central bay infilled with a RC wall ( $2.1 \mathrm{~m}$ net span). The structure had a total height of $12 \mathrm{~m}$ and the perpendicular distance between the South and North frames was $6.25 \mathrm{~m}$. It must be noted here that the building's frame was designed based on the old Cyprus code used in the 1970's, which is now replaced by Eurocode (2003), whereas designers use KANEPE (2012) that was developed in Greece and it is currently considered to be the most comprehensive code in retrofitting design. Fig. 5 shows the geometrical details of the south frame and in Fig. 6 the 4-storey RC specimen can be seen prior to testing. The reinforcement details of the different structural members can be depicted in Fig. 7, as they were reported in Martin et al. (2013).

According to the experimental setup Martin et al. (2013), the concrete material used for the construction of the RC frame was a C20/25 for all structural members. The uniaxial compressive strength was $f_{c}=20 \mathrm{MPa}$ with a Young Modulus of elasticity equal to $E_{c}=30 \mathrm{GPa}$ and a unit weight of $25 \mathrm{kN} / \mathrm{m}^{3}$. These were also the values used in the numerical investigation presented in section 5 of this manuscript. The steel rebar material properties that were used to perform the numerical investigation, also complied with the ones found within the technical report (Martin et al. 2013), which foresaw the use of 400 and $450 \mathrm{MPa}$ of yielding stress bars. The $400 \mathrm{MPa}$ steel material was used to reinforce the RC frame without the infill walls, while the $450 \mathrm{MPa}$ steel material was used for the rebars that were placed within the infill RC walls. The Young Modulus of elasticity was not reported in Martin et al. (2013) for either steel bars thus an $E_{s}=190 \mathrm{GPa}$ was adopted herein for the needs of the numerical analysis.

The loads that were applied on the specimen assumed that each floor was loaded with a $3 \mathrm{kN} / \mathrm{m}^{2}$ (dead load) and a $0.45 \mathrm{kN} / \mathrm{m}^{2}$ live load (this represented the $30 \%$ of the characteristic live load and complied with the Eurocode provisions). Therefore, the same load magnitudes were applied on the FE model including the self-weight of the frame. It must be noted here that the vertically imposed loads were applied on the RC specimen through the use of water barrels located between the actuator attachment beams that were used to apply the horizontal displacements during the experiment. The actuator beams were positioned at a distance of $1.4 \mathrm{~m}$ from the two frames, respectively, while the 
distance between the actuator attachment beams was $3.45 \mathrm{~m}$.

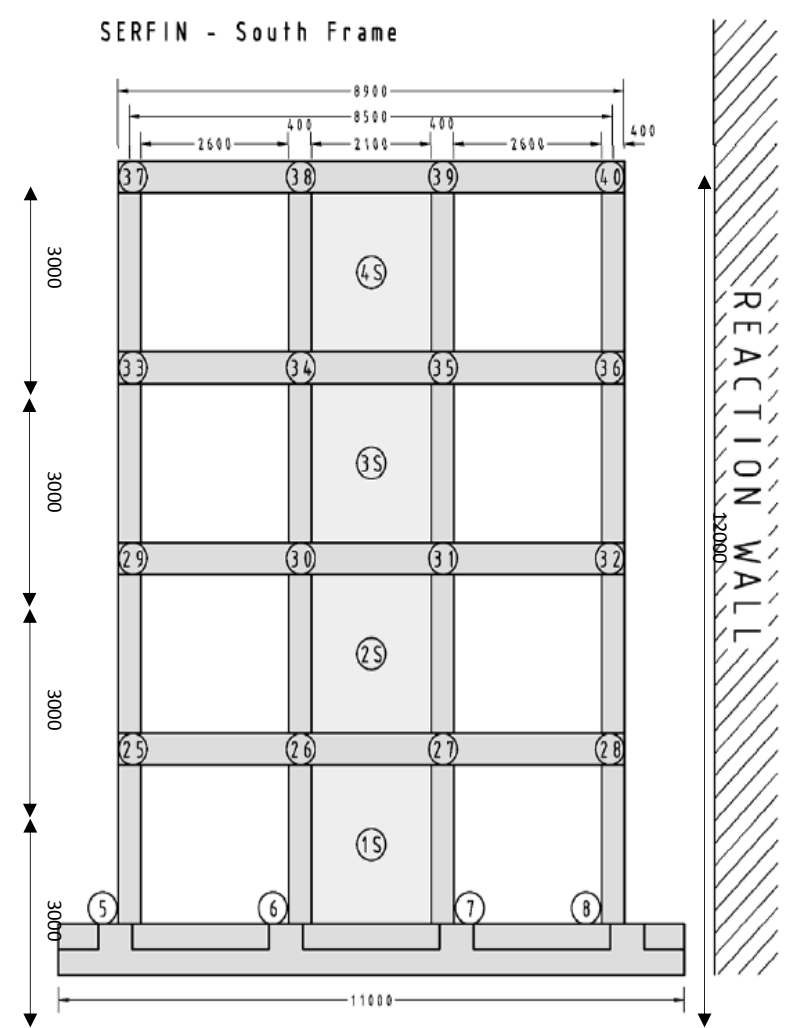

Fig. 5. South frame's geometrical details. (Martin et al. 2013)

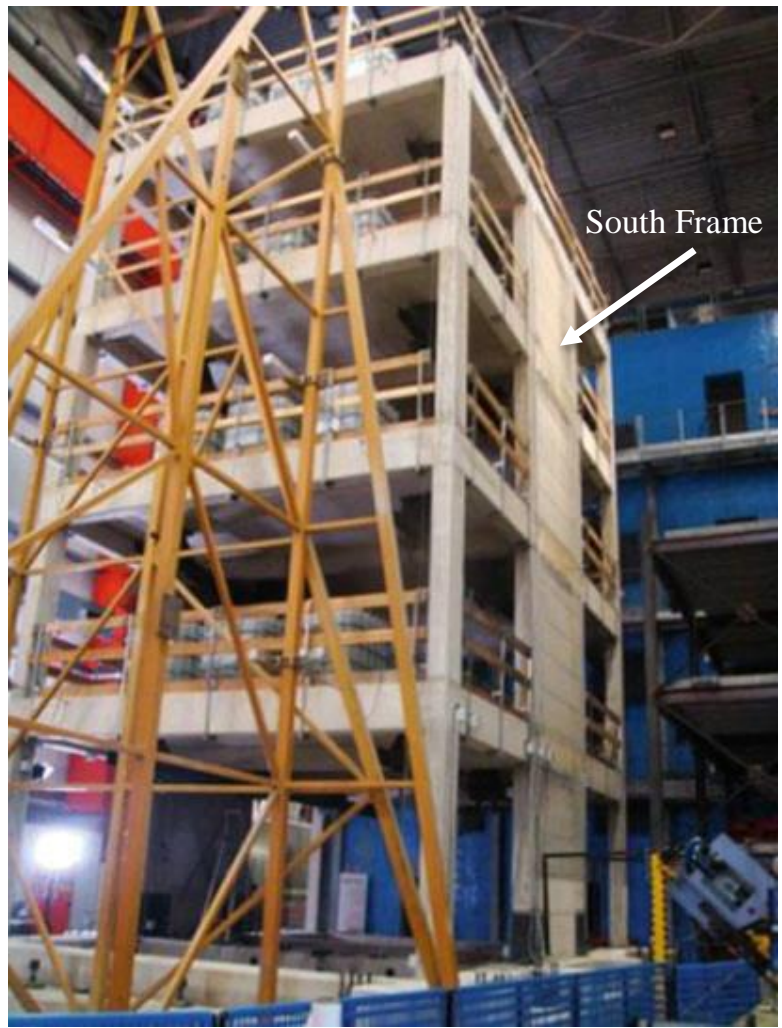

Fig. 6. 4-storey RC specimen in the lab. (Kyriakides et al. 2015)

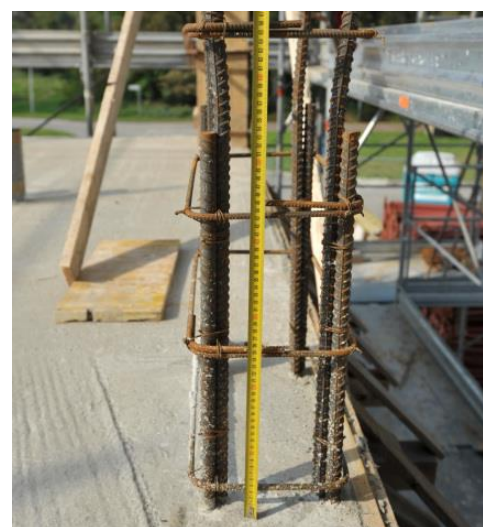

a. Column reinforcement

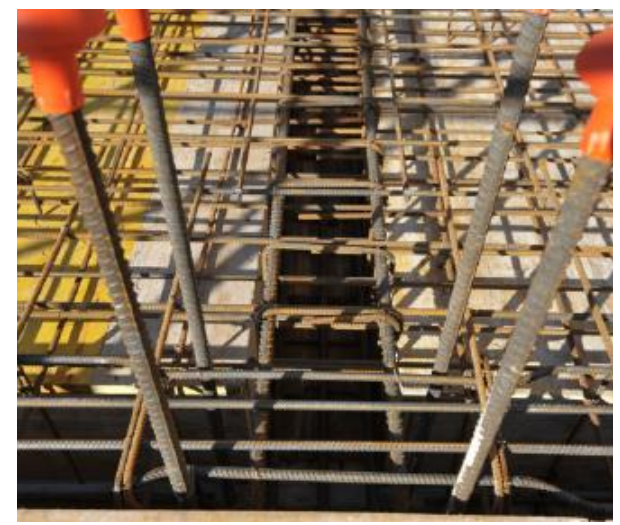

b. Central beam and slab reinforcement

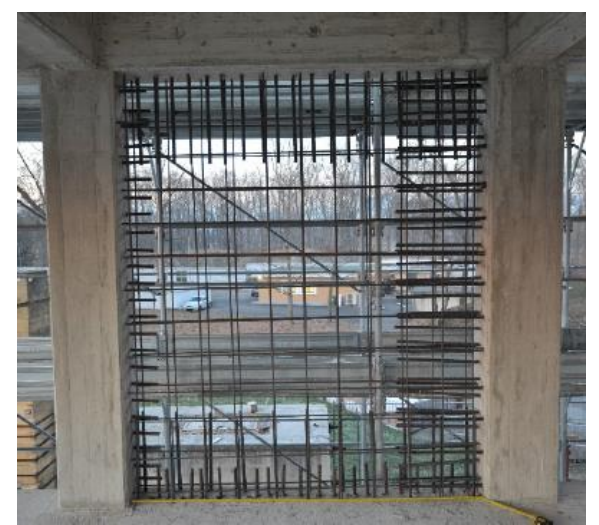

c. Infill shear wall reinforcement

Fig. 7. Reinforcement details of the RC fame. (Martin et al. 2013)

In regards to the loading histories that were chosen to be applied on the structure, the experiment foresaw three different loading sets that corresponded to three independent earthquake intensity levels. The first loading history derived the displacements shown in Fig. 8a and was scaled in order to represent a low seismic acceleration of $0.1 \mathrm{~g}$. For the case of the second loading test, the applied loads resulted by using a high acceleration equal to $0.25 \mathrm{~g}$, where the slab displacements that were recorded at each storey can be depicted in Fig. 8b. The final set of displacements were obtained based on the last set of loading cycles applied on the building that intended to reach the specimen's maximum capacity. The corresponding displacements that derived from the $3^{\text {rd }}$ and last loading set ("funeral cycles") can be seen in Fig. 8c. Based on this diagram, it is easy to observe that the horizontal displacements at the top floor were equal to $92,-92,89,-125,37$ and $0 \mathrm{~mm}$. During the "funeral cycles", the structure was pushed and at the same time the base shear of the building was measured in order to observe for any sudden capacity drops (as it was reported by Kyriakides et al. 2015). During the test, the building demonstrated a sudden drop when the horizontal displacement at the roof slab reached $125 \mathrm{~mm}$ (negative horizontal deformation), where it was assumed that the frame reached its ultimate resistance. 


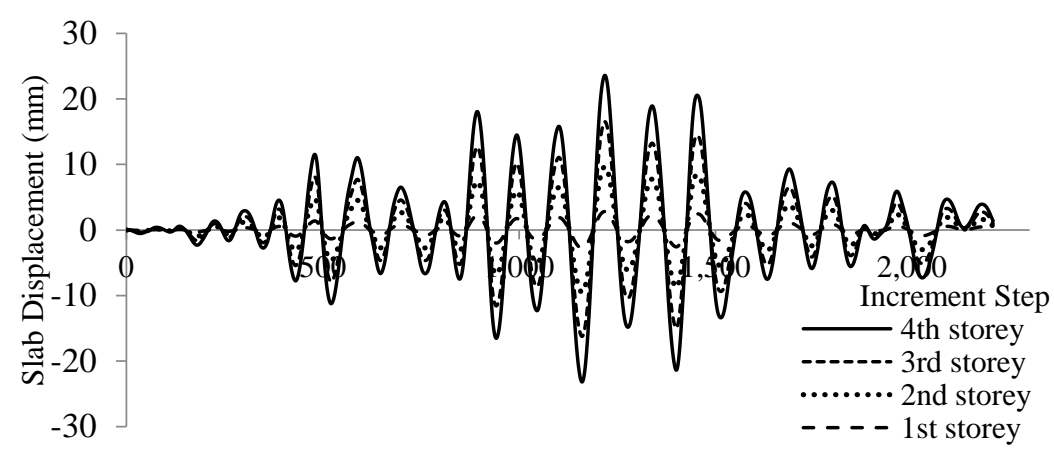

a. $0.1 \mathrm{~g}$ test

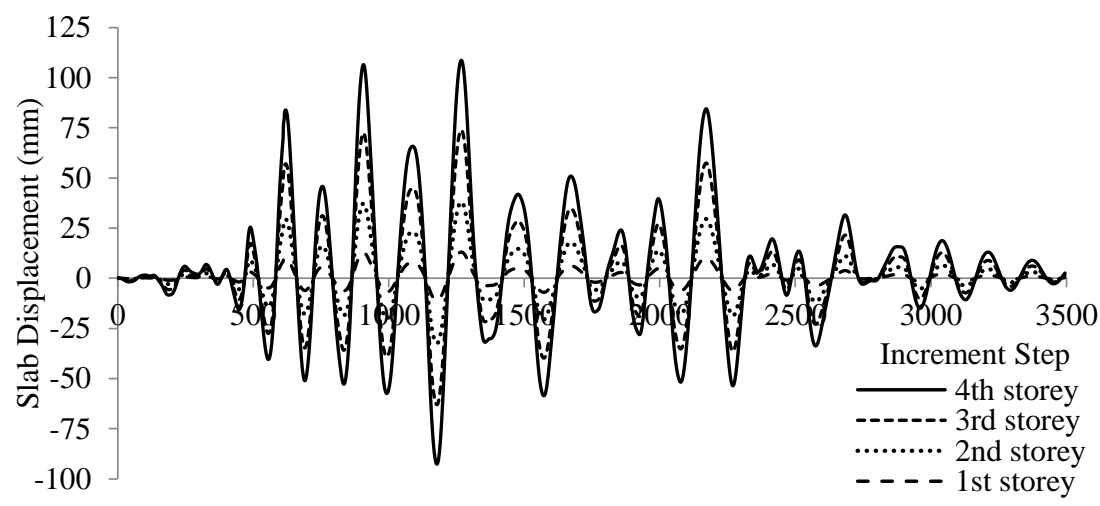

b. $\quad 0.25 \mathrm{~g}$ test

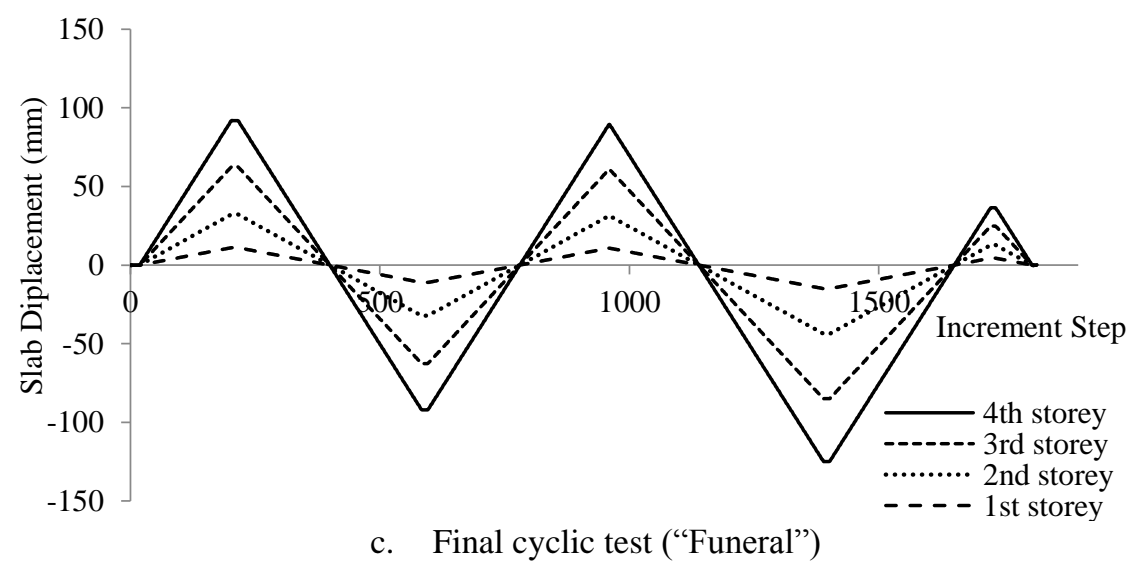

Fig. 8. Displacement histories of the specimen.

\section{Numerical Model, Results and Discussion}

The numerical model and the analysis results will be presented in this sections, for all three loading histories, in an attempt to reveal the modeling capabilities (in terms of accuracy and computational efficiency) of the proposed HYMOD approach. It must be noted here that, an energy convergence criterion was used for all the numerical nonlinear simulations as expressed in Eq. 10. According to the numerical findings presented in Markou et al. (2018), the optimum convergence energy tolerance that will reassure both accuracy and numerical stability is $10^{-5}$, which is the value that was adopted in this work. In addition to that, the CPU used to perform all the analyses presented in this section, had a 4.2 $\mathrm{GHz}$ computing power.

$$
\boldsymbol{e}_{e r r}=\frac{\Delta u_{s}^{j}\left\|\boldsymbol{F}_{s}^{t+\Delta t}-\boldsymbol{R}_{s}^{t+\Delta t}\right\|}{\Delta u_{s}^{I}\left\|\boldsymbol{F}_{s}^{t+\Delta t}-\boldsymbol{R}_{s}^{t}\right\|} \leq \text { tolerance }
$$

\subsection{Finite Element Mesh}

In this section, a brief presentation of the HYMOD FE mesh that was developed for the analyses needs, will take place. As it can be seen in Fig. 9, the 3D detailed full hexahedral FE mesh is shown, 
which consists of 16,662 hexahedrons according to Table 1 (excluding the CFRP jacketing elements) and 31,246 embedded rebar elements. This model discretized the exact geometry of the 4-storey RC specimen, while the embedded rebar elements were modeled based on the exact steel reinforcement geometry (Fig. 9) reported in Martin et al. (2013). The Full Hexa model was found to have a very high computational demand (Markou et al. 2017) that made it practically prohibitive to be used for any type of nonlinear analysis. Thus the construction of the HYMOD mesh was performed by applying a reduction level 1 (for additional details regarding reduction levels see Markou and Papadrakakis 2015) that foresaw the deletion of all hexahedral elements found at beam and column structural members, as illustrated in Fig. 10. The resulted HYMOD mesh presented in Fig. 10, where the concrete and reinforcement FE meshes can be seen, managed to decrease the initial number of elements by $39 \%$ and the initial dofs by $48 \%$ (see Table 1 ).

As it was shown in Mourlas et al. (2017), using the full model is an option when it comes to push over analyses given that the number of increments is relatively small. Using 10 or 20 load increments during the analysis can be computationally feasible even in the case of a 5-storey building (Bark et al. 2016) that is discretized through the use of 20-noded hexahedral finite elements. Nevertheless, the computational demand was found to be excessive in this case, given that the nonlinear solution procedure required days to complete due to the large number of elements. When it comes to the numerical solution of nonlinear cyclic analysis of full-scale structures under realistic laboratory conditions (hundreds of load increments), this approach is no longer a feasible option due to the increased computational demand during the nonlinear solution procedure.

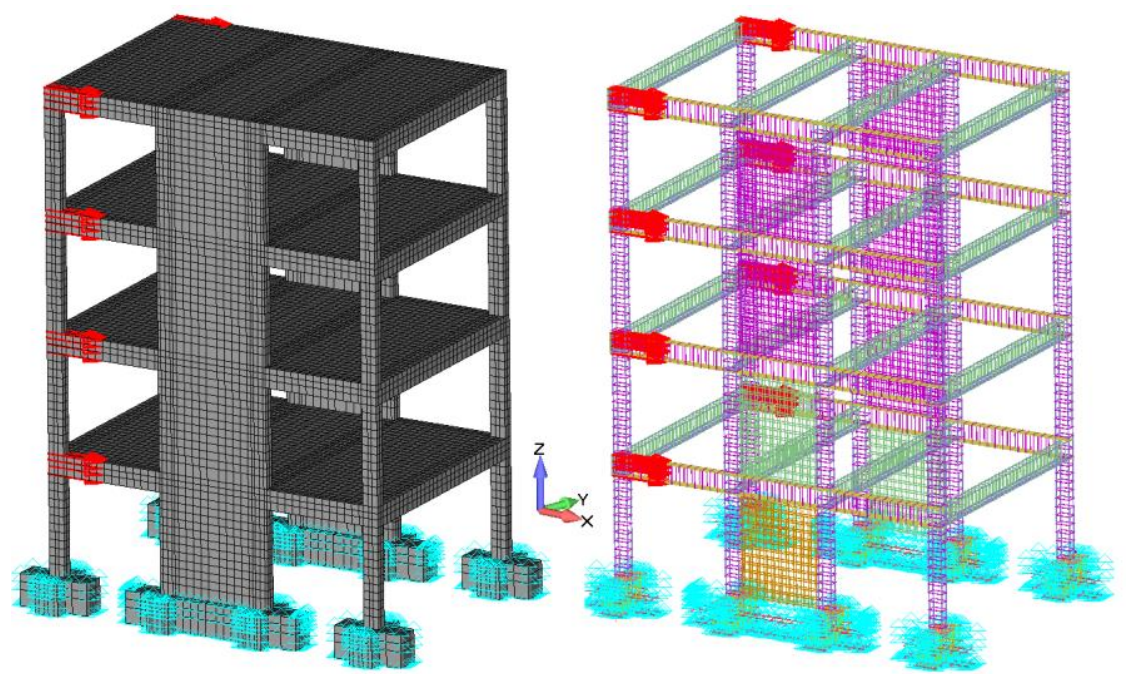

Fig. 9. Full Hexa FE mesh. (Left) Discretization of the concrete domain and (Right) Embedded rebar elements. (Markou et al. 2017)
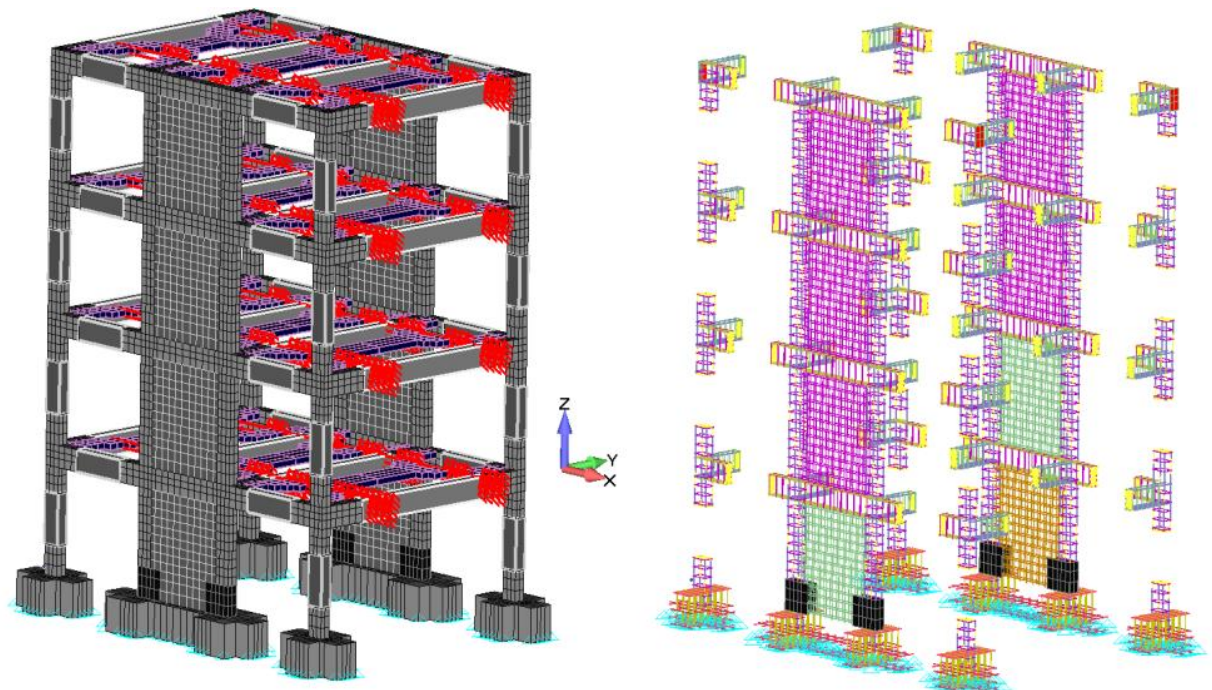

Fig. 10. HYMOD FE mesh. (Left) Discretization of the concrete domain and (Right) Embedded rebar elements. (Markou et al. 2017) 
Table 1 FE mesh details of the 4-storey RC frame models.

\begin{tabular}{|c|c|c|c|c|c|c|c|}
\hline a/a & Model & $\begin{array}{c}\text { Hexahedral } \\
\text { Elements }\end{array}$ & $\begin{array}{c}\text { Embedded } \\
\text { Rebar } \\
\text { Elements }\end{array}$ & $\begin{array}{c}\text { RC } \\
\text { NBCFB } \\
\text { Elements }\end{array}$ & $\begin{array}{c}\text { Hexa FE } \\
\text { Reduction } \\
(\%)\end{array}$ & $\begin{array}{c}\text { Embedded } \\
\text { Rebar FE } \\
\text { Reduction } \\
(\%)\end{array}$ & $\begin{array}{c}\text { Overall FE } \\
\text { Reduction } \\
(\%)\end{array}$ \\
\hline 1 & Full Hexa & 16,662 & 31,246 & - & - & - & - \\
\hline 2 & HYMOD & 8,356 & 20,646 & 48 & 49.85 & 33.92 & 39.46 \\
\hline a/a & Model & $\begin{array}{c}\text { Stiffness } \\
\text { Matrix Size } \\
(\text { Mb) }\end{array}$ & $\begin{array}{c}\text { Reduction in Stiffness } \\
\text { Matrix Size } \\
(\%)\end{array}$ & Dofs & $\begin{array}{c}\text { Dofs } \\
\text { Reduction } \\
(\%)\end{array}$ & - \\
\hline 1 & Full Hexa & 1,000 & - & 85,191 & 48.47 \\
\hline 2 & HYMOD & 335 & \multicolumn{2}{c|}{66.5} & 43,896 & 48.4 \\
\hline
\end{tabular}

The HYMOD mesh presented in Fig. 10 foresaw the discretization of all shear dominated areas of the framing system through the use of the 3D detailed approach, while the rest of the structure was modeled through the use of the NBCFB FE (beam and column structural members). In order to take into account a realistic plastic hinge length when performing the mesh reduction, the recommended hinge length was used as proposed in Markou and Papadrakakis (2015) (h-2h, where $\mathrm{h}$ is the height of the beam or column section). Therefore, the beams within the South and North frames' plane where assigned a $60 \mathrm{~cm}$ hinge length, while the out-of-plane beams had a hinge length of $100 \mathrm{~cm}$. The columns of the frame were discretized by using the same concept, where the plastic hinge length was set to $70 \mathrm{~cm}$. The hexahedral element sizes that were used so as to discretize the RC frame, varied between 10 to $20 \mathrm{~cm}$ along all global directions ( $\mathrm{x}, \mathrm{y}$ and $\mathrm{z}$ ). The only exception in this rule, were the hexahedral elements that were used to discretize the diaphragmatic behavior of the slabs (see Fig. 10). The longer elements that can be seen in these figures were constructed in an attempt to further decrease the slab's mesh without losing the corresponding numerical accuracy.

The imposed displacement histories were applied through kinematic constraints at the nodes of the four slabs that were located at the points of the actuator attachment beams-slab connections as can be seen in Fig. 10. The displacement histories that were applied on each slab where based on the displacements published in Martin et al. (2013). Furthermore, as it was stated in the technical report Martin et al. (2013), the load that was applied through the two actuator attachment beams at each slab, was controlled and monitored so as to avoid any torsion development in the building. This also complies to the numerical method that was used to implement the imposed displacements as shown in Fig. 10 (applying the same displacement functions along two parallel lines along each slab).
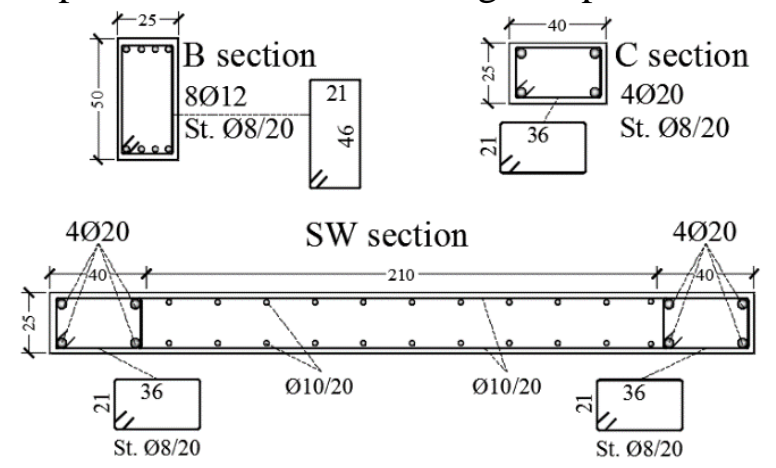

Fig. 11. Geometric and reinforcement details of the South and North RC Frames'sections $(Ø \mathrm{~mm} / \mathrm{cm})$.

The reinforcement details that refer to the shear walls, the in plane beams and columns of the two $\mathrm{RC}$ frames, are shown in Fig. 11. It must be also noted here that, the infill wall reinforcement varies and it is not identical for the North and South frames. This was intentionally done according to the experiment's design, while it was also accounted for in the developed model depicted in Fig. 10. Furthermore, the constitutive model for the case of bond slippage that was used during the cyclic analysis, foresaw the use of a full bond assumption that complied with the experimental findings. Fig. 12 shows the embedded rebar details of the shear wall's boundary columns and the infill area. As it can be observed in this figure, the full bond assumption gave also the ability to avoid the modeling of the dowel rebars that were used to achieve a solid connection between the old and new concrete material. Furthermore, this helps to simplify the modeling of the structure's rebars, while further 
decreases the computational cost of the model during the nonlinear cyclic analysis. The foundation reinforcement located under the retrofitted structural member can also be seen in the same figure.

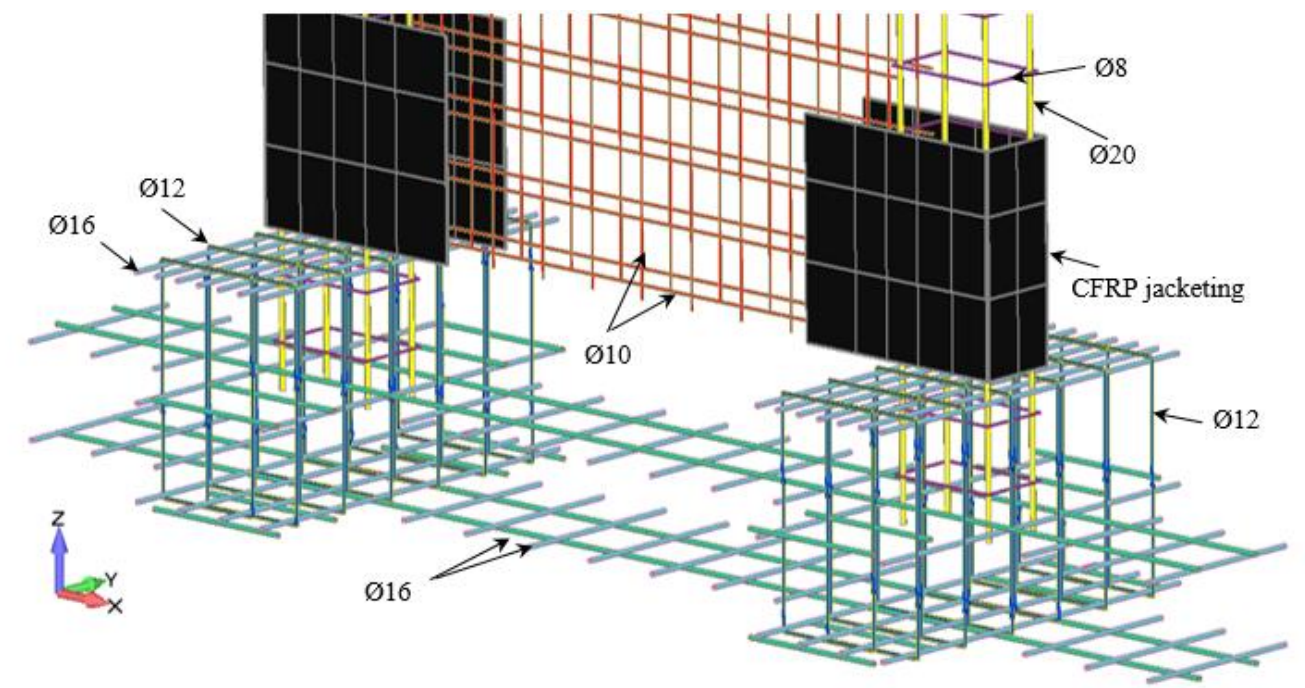

Fig. 12. FE mesh of the reinforcement details of the South shear wall and its foundation (different colors represent different rebar dimeters).

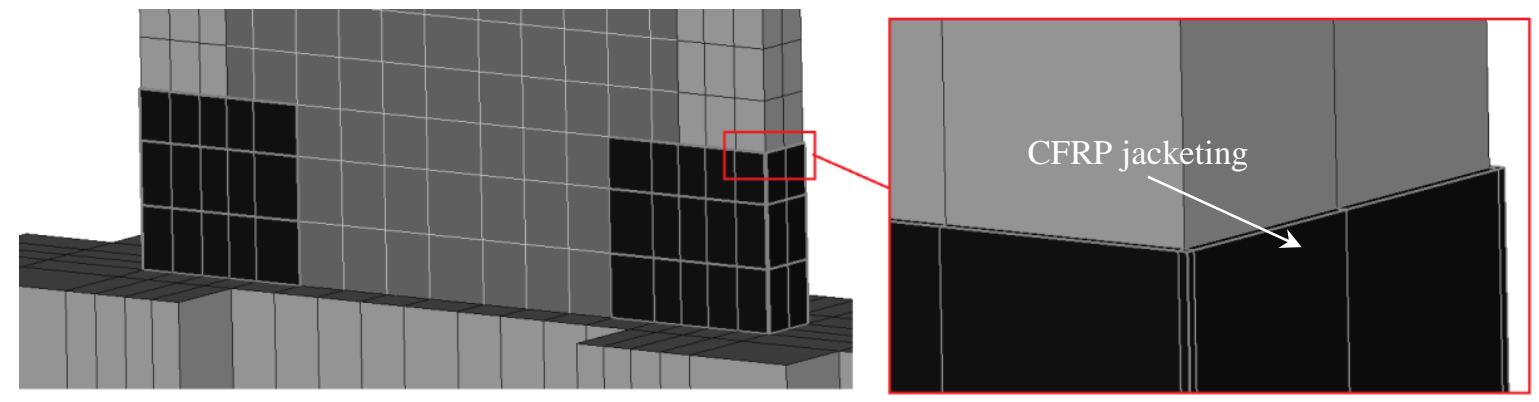

Fig. 13. Discretization of the CFRP jacketing through the use of hexahedral elements.

Table 2 Material details used in the FE model.

\begin{tabular}{|l|c|c|c|c|c|c|c|}
\hline \multicolumn{1}{|c|}{ Material } & $\begin{array}{c}\text { Young } \\
\text { Modulus } \\
(\mathrm{GPa})\end{array}$ & $\begin{array}{c}\text { Hardening } \\
\text { Modulus } \\
(\mathrm{GPa})\end{array}$ & $\begin{array}{c}\text { Yielding Stress / } \\
\text { Tensile Strength } \\
\text { (MPa) }\end{array}$ & $\begin{array}{c}\text { Compressive } \\
\text { Strength } \\
(\mathrm{MPa})\end{array}$ & $\begin{array}{c}\text { Shear } \\
\text { remaining } \\
\text { strength } \beta\end{array}$ & $\begin{array}{c}\text { Poisson } \\
\text { Ratio }\end{array}$ & $\begin{array}{c}\text { Ultimate } \\
\text { Strain } \\
\varepsilon\end{array}$ \\
\hline Concrete & 30 & - & $2^{*}$ & 20 & 0.2 & 0.2 & - \\
\hline $\begin{array}{l}\text { Steel inside } \\
\text { the Frame }\end{array}$ & 190 & 2.1 & 400 & - & - & 0.3 & $15 \%$ \\
\hline $\begin{array}{l}\text { Steel inside } \\
\text { the Infill Walls }\end{array}$ & 190 & 2.1 & 450 & - & - & 0.3 & $15 \%$ \\
\hline CFRP & 100 & - & $1,000^{*}$ & 1,000 & - & 0.3 & $1 \%$ \\
\hline
\end{tabular}

As it was mentioned above, the CFRP jacketing was discretized through the use of 8-noded hexahedral elements (Figs. 12 and 13). The CFRP jacketing was included in the final HYMOD mesh given that it played a significant role in the overall execution of the experiment as reported in Kyriakides et al. (2015). Therefore, this additional retrofitting method was also discretized and modeled herein. The embedded rebar elements were modeled through the use of the beam element, while the material properties that were used during all analyses are summarized and presented in Table 2. All the values for each property that were defined in the FE model were found in the SERFIN project's report (Martin et al. 2013), except from the CFRP jacketing material properties that were not provided.

The analyses that were performed in this research work, were static cyclic displacement control analyses that used the Newton-Raphson nonlinear solution algorithm. The displacement increment was defined according to the number of displacement increments per loading cycle so as to avoid large displacement steps that would lead to large numbers of internal iterations and potential numerical instabilities. The displacement increment was selected based on the numerical findings presented in Markou et al. (2018) and a general rule that derived from this work that requires the use of a step that 
will not allow the development of numerical instabilities when a large displacement increment is used. In this case, a displacement increment that was equal or less than $2 \mathrm{~mm}$ was adopted throughout the analyses.

\subsection{Analysis Results for the $0.1 \mathrm{~g}$ Test}

The first set of imposed cyclic loading (as reported in Markou et al. 2017) was performed according to the displacement histories that derived from a loading set, which represented a low intensity earthquake excitation of a $0.1 \mathrm{~g}$ maximum acceleration. Each slab was displaced and the corresponding base shear was computed by using the HYMOD mesh shown in Fig. 10. As it was reported by Kyriakides at al. (2015), the structure developed hairline cracks that appeared on the surface of the wall that were eventually closed down when the first cyclic loading history was finished. This implies that the structure entered the nonlinear state from the very first set of loading cycles, which implies that concrete had developed cracks that should be accounted for during the second stage of loading test. It must be noted here that, the maximum horizontal displacement at the top floor, according to the experimentally obtained displacement history, was $23.5 \mathrm{~mm}$ along the positive $\mathrm{x}$-axis and $23 \mathrm{~mm}$ along the negative.

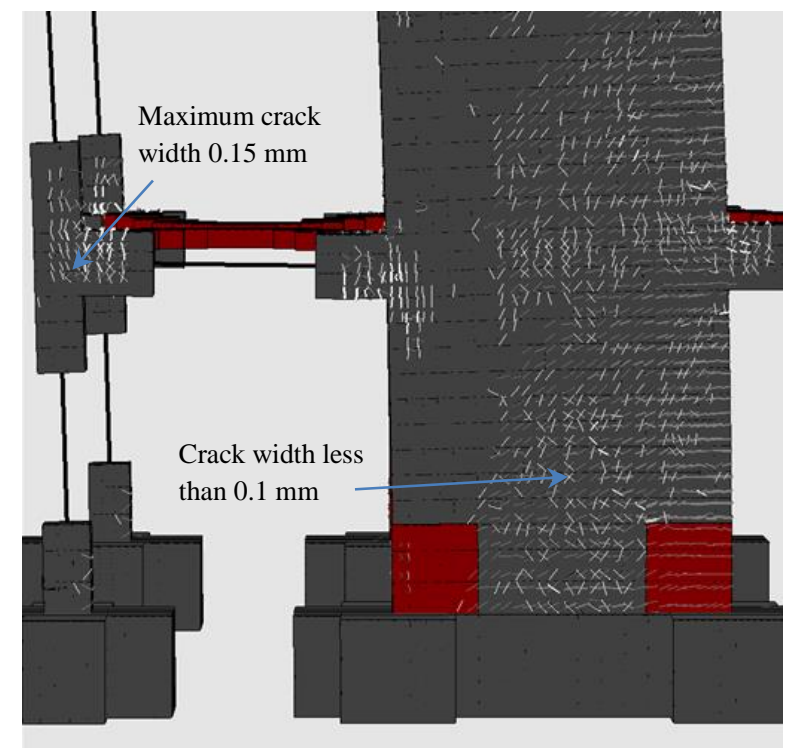

a.

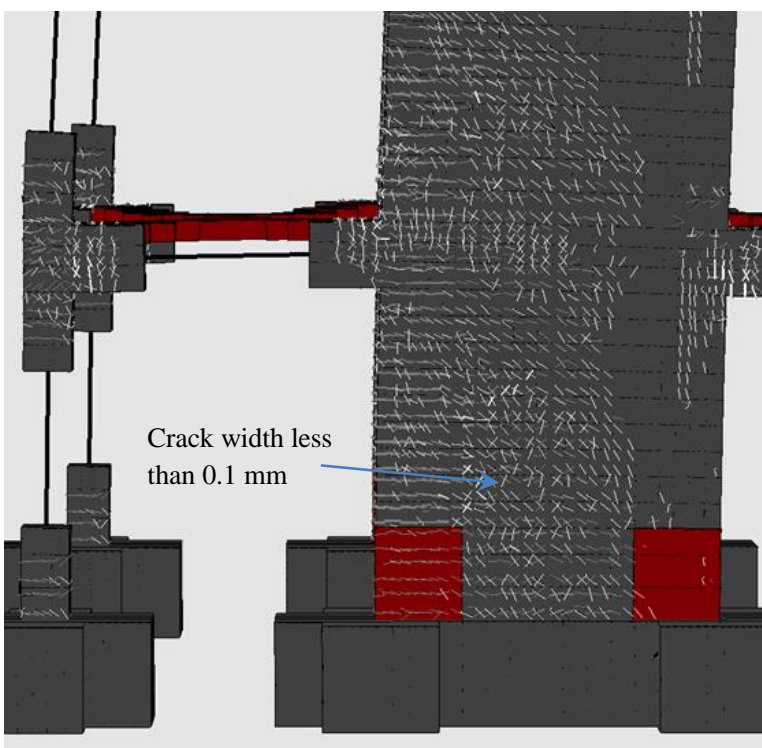

b.

Fig. 14. $1^{\text {st }}$ loading test $(0.1 \mathrm{~g})$. Crack pattern of the South wall for (a) $\delta_{\mathrm{H}}=-23 \mathrm{~mm}$ and (b) $\delta_{\mathrm{H}}=23.5 \mathrm{~mm}$. Maximum computed crack width $0.15 \mathrm{~mm}$. (Markou et al. 2017)

Martin et al. (2013) reported that the walls developed diagonal cracks that closed after the load test was completed, which complies with the numerically computed crack pattern. For the case of the two maximum horizontal displacements (negative and positive), Figs. 14a and 14b show the numerically derived crack patterns and their maximum width, according to the Markou et al. (2017) findings. In addition to that, the opening and closing of cracks can be easily observed from these two figures, highlighting the numerical ability of the proposed opening-closing criterion that was proposed in Mourlas et al. (2017) to handle this complex numerical phenomenon. It must be noted here that, the crack width was calculated by multiplying the computed principal strain, which was developed perpendicularly to the crack plane, with the corresponding size of the hexahedral finite element along the normal direction.

As reported by Markou et al. (2017), Fig. 15 shows the comparison between the numerical and experimental base shear-horizontal displacement curves, where it can be seen that the HYMOD managed to capture the maximum experimental base shear with high accuracy for this first loading test. For the case of the numerically predicted von Mises contours and for more information in regards to the numerical results that were obtained from the $1^{\text {st }}$ loading test, please see Markou et al. (2017). 


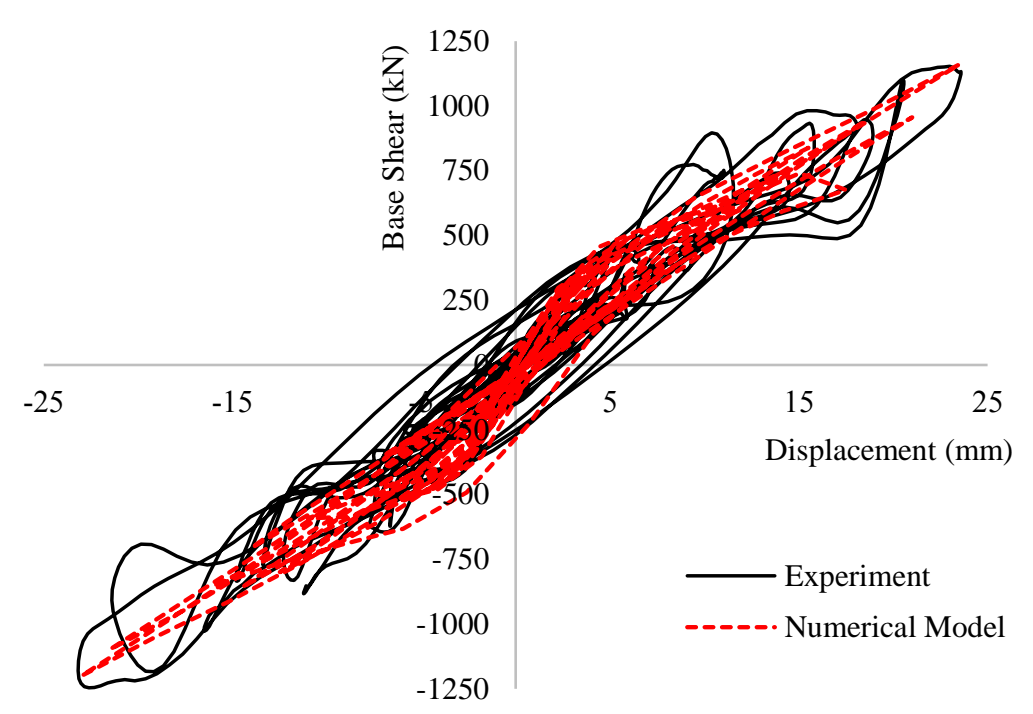

Fig. $15.1^{\text {st }}$ loading test $(0.1 \mathrm{~g})$. Experimental vs numerical curves. Total base shear-horizontal displacement of the top floor. (Markou et al. 2017)

\subsection{Analysis Results for the $0.25 \mathrm{~g}$ Test}

A more numerically rigorous problem had to be solved in order to simulate the mechanical behavior of the RC structure due to the $0.25 \mathrm{~g}$ test, according to the experimental loading campaign. As it was shown in Fig. 8 b, the $2^{\text {nd }}$ displacement history obtained from this test, foresaw the application of 24 loading cycles with a resulted positive maximum displacement equal to $108 \mathrm{~mm}$ and a corresponding negative of $92 \mathrm{~mm}$. A total of 1,440 displacement increments were solved for the needs of this nonlinear problem, where the convergence tolerance that was used during the nonlinear analysis was set again to $10^{-5}$. The initial undamaged numerical model developed in section 5.1 was also used to solve this $2^{\text {nd }}$ loading test, without any modifications to the mesh or the material properties. The reasons why the entire loading history of the experiment ( 3 load tests; $0.1 \mathrm{~g}, 0.25 \mathrm{~g}$ and "funeral") was not applied through a single run, were purely computational and hardware related. Only for the output file, it was estimated that more than a $200 \mathrm{~Gb}$ of hard drive space and a $70 \mathrm{~Gb}$ of RAM for solving the entire numerical problem would have been required. Therefore, this would have exceeded the available installed RAM in the PC, which was used to perform the numerical investigation.

The numerically computed base shear vs horizontal displacement curve (dashed line) is compared with the corresponding experimental one in Fig. 16. It is easy to notice that the numerical model, which used the undamaged concrete material properties, exhibited a stiffer behavior than the experimental curve (for the case of positive displacements). This numerical finding is attributed to the fact that the concrete damage developed during the first loading test was not numerically accounted for during the second numerical experiment. In order to remedy this problem, a second displacement history set was developed and applied on each slab based on the diagram shown in Fig. 17. As it can be seen, the new loading cycles foresee two preparatory cycles that have an absolute maximum magnitude of 20 and $23 \mathrm{~mm}$ horizontal displacements at the top floor, respectively. This two cycles were developed based on the maximum horizontal displacements derived during the first loading test (Fig. 8a), where the choice of only two preparatory cycles (in addition to the $2^{\text {nd }}$ loading test history) was made to avoid the significant increase in terms of computational demand. The new total number of displacement increments solved during the new analysis was 1,560, whereas the new obtained curve is shown in Fig. 16.

Based on the second numerical experiment (see Fig. 16), the HYMOD managed to capture the experimental data with high accuracy, given that the maximum predicted base shear capacity of the building along the positive and negative $\mathrm{x}$-axis were found to be within a $10 \%$ margin and always in favor of safety. In addition to that, the ability of the HYMOD to capture the hysteretic loops is also evident, while the material model used for the concrete simulation demonstrates its ability to numerically account for the concrete strength degradation due to the multiple loading cycles. 


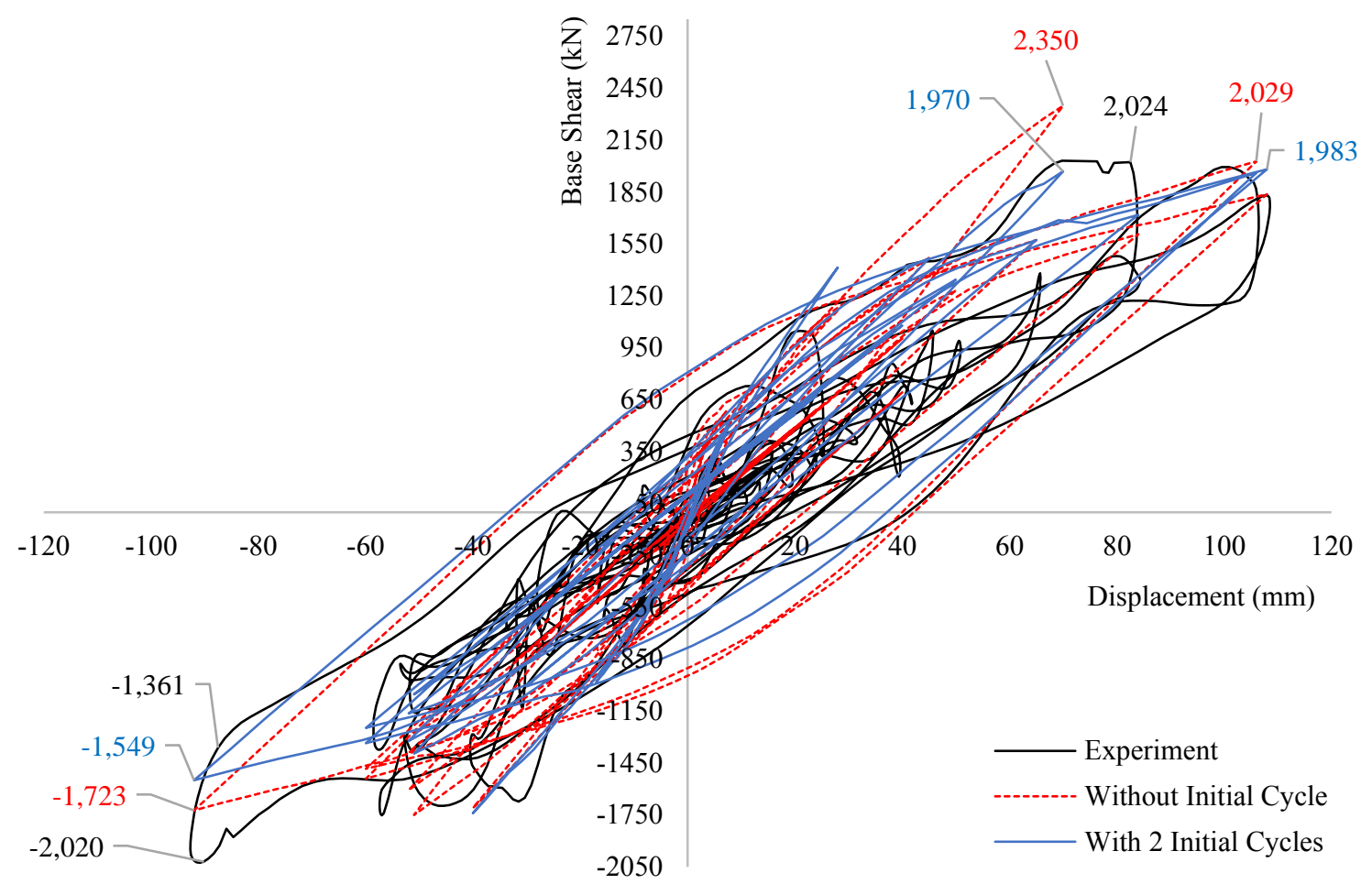

Fig. 16. $2^{\text {nd }}$ loading test $(0.25 \mathrm{~g})$. Experimental vs numerical curves. Total base shear-horizontal displacement of the top floor.

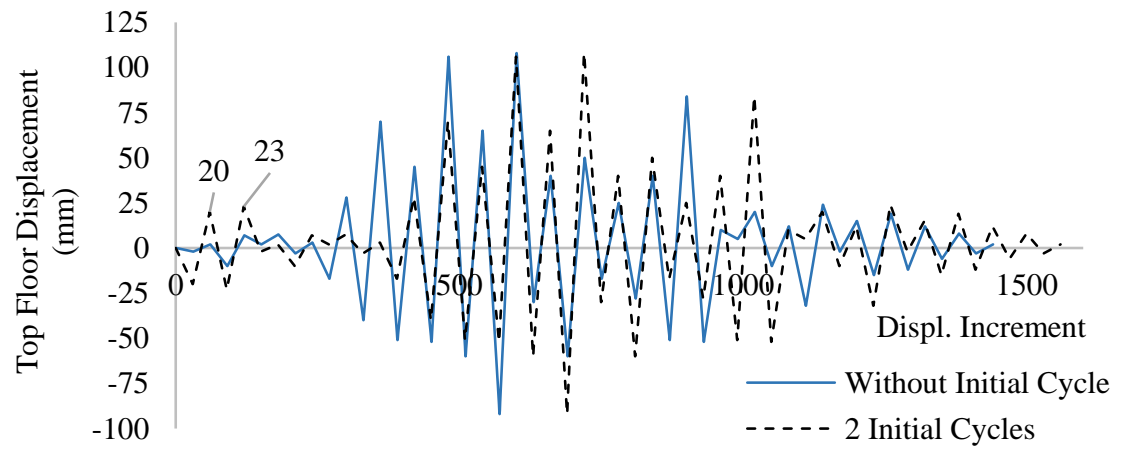

Fig. $17.2^{\text {nd }}$ loading test $(0.25 \mathrm{~g})$. Displacement history with 2 initial preparatory cycles applied at the top floor.

Figs. 18 and 19 show the von Mises strain contours that were numerically computed at the two frames, South and North, respectively, for the two maximum (positive and negative) horizontal roof displacements. As it can be seen, the South frame was found to be the one that developed more damages given that the reinforcement ratio used (based on the design of its RC infill wall) was lower compared to that of the North frame. In order to further investigate the deformation history at different areas of the structural frame, 4 strain history diagrams were developed at 8 different locations labeled as (S1, S2, S3, S4) and (N1, N2, N3, N4), which can be seen in Figs. 18 and 19, respectively. The selected points were chosen to be located at areas where the strain concentration was found to be high, while the N4 and S4 locations were chosen so as to study the numerically predicted concrete confinement effect due to the CFRP jacketing. It is important to state here that, for the locations N1 and $\mathrm{S} 1$, the strain along the global $\mathrm{x}$-axis (direction of the horizontal displacement) was studied given that they are located at the bottom fiber of the beams' sections (ground floor slab), while for the rest of the locations that are located at vertical structural members (columns and walls), the $\mathrm{z}$-axis strain was chosen to be graphically visualized. 


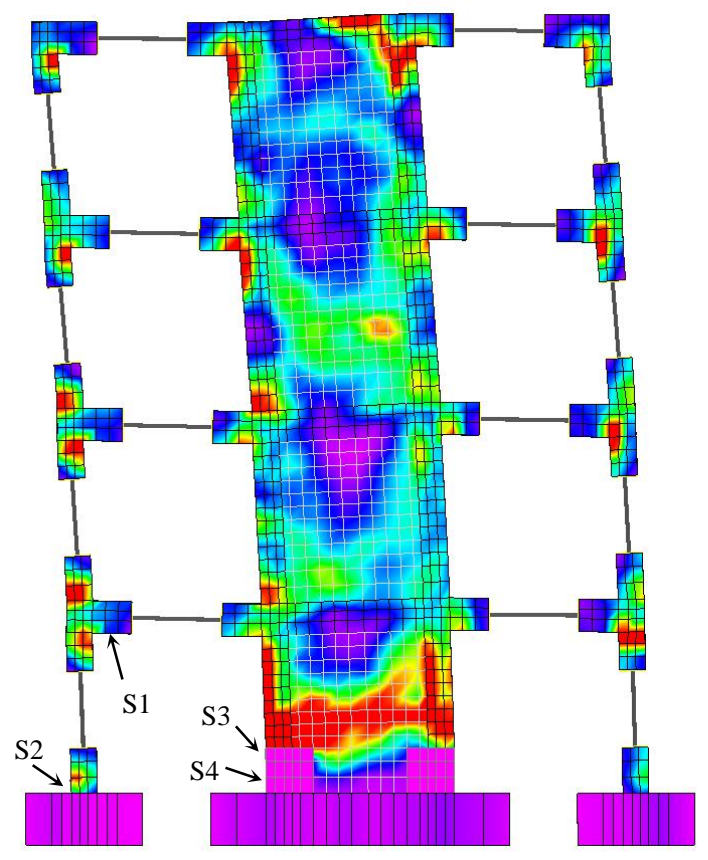

a.

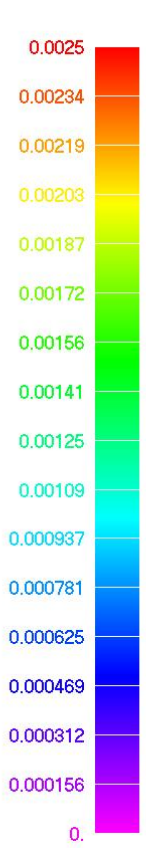

0.

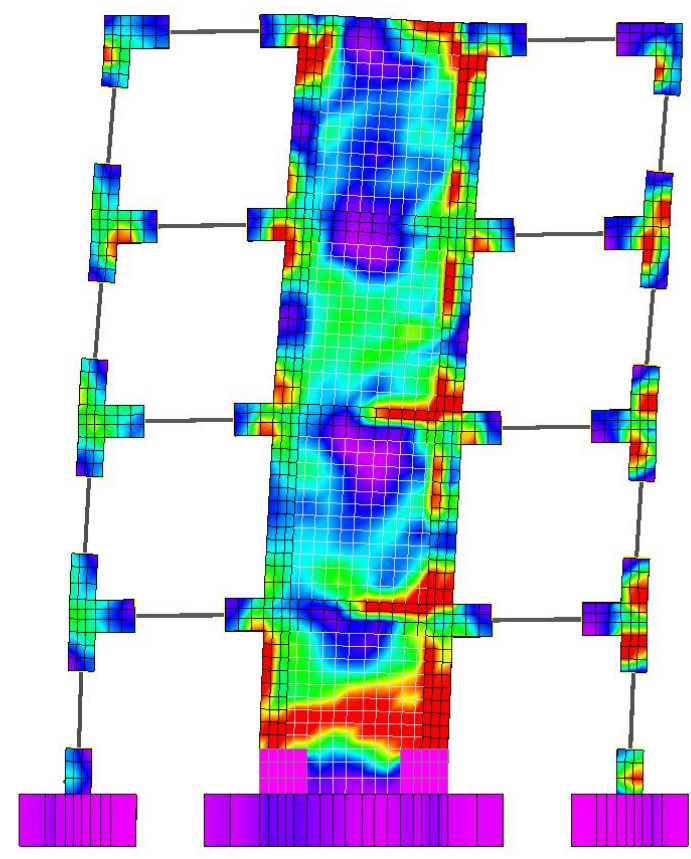

b.

Fig. 18. $2^{\text {nd }}$ loading test $(0.25 \mathrm{~g})$. Von Mises strain contour for displacement increments (a) $690\left(\delta_{\mathrm{H}}=-92 \mathrm{~mm}\right)$ and $(\mathrm{b})$ $720\left(\delta_{\mathrm{H}}=108 \mathrm{~mm}\right)$. South frame.

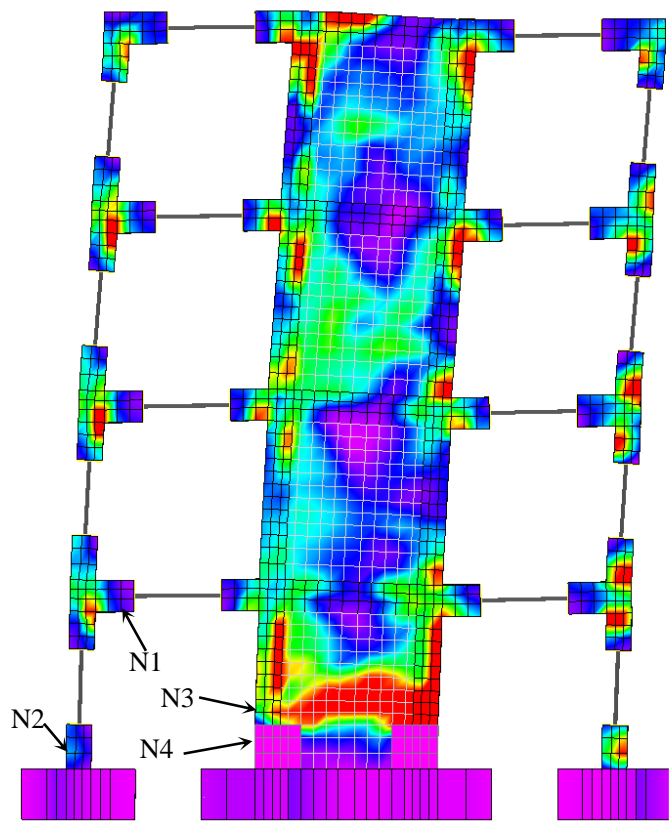

a.

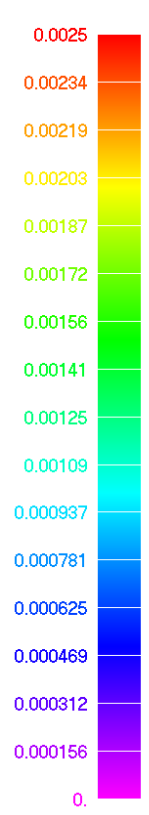

0.

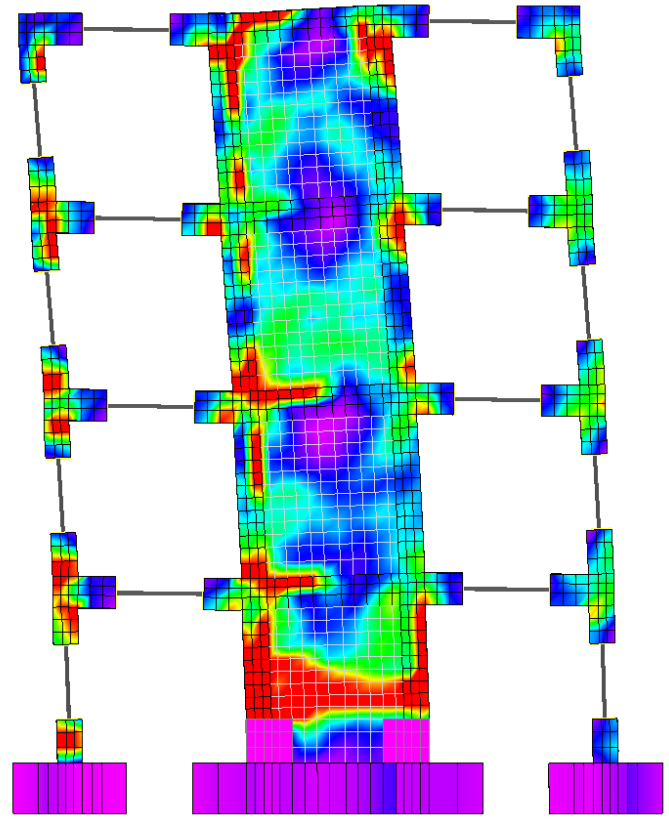

b.

Fig. 19. $2^{\text {nd }}$ loading test $(0.25 \mathrm{~g})$. Von Mises strain contour for displacement increments (a) $690\left(\delta_{\mathrm{H}}=-92 \mathrm{~mm}\right)$ and $(\mathrm{b})$ $720\left(\delta_{\mathrm{H}}=108 \mathrm{~mm}\right)$. North frame.

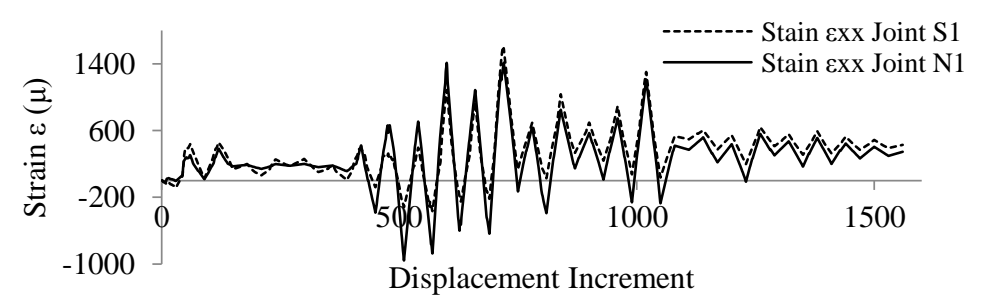

Fig. $20.2^{\text {nd }}$ loading test $(0.25 \mathrm{~g})$. Numerically computed strain $\varepsilon_{\mathrm{x}}$ history at the points $\mathrm{N} 1$ and S1. 


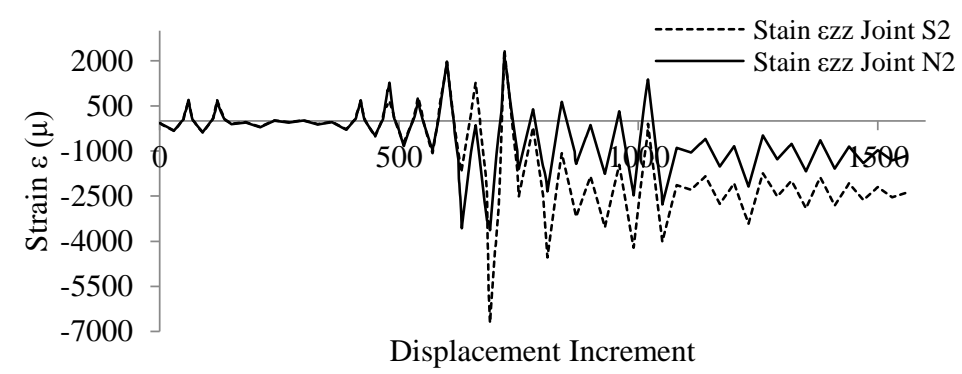

Fig. 21. $2^{\text {nd }}$ loading test $(0.25 \mathrm{~g})$. Numerically computed strain $\varepsilon_{\mathrm{z}}$ history at the points $\mathrm{N} 2$ and $\mathrm{S} 2$.

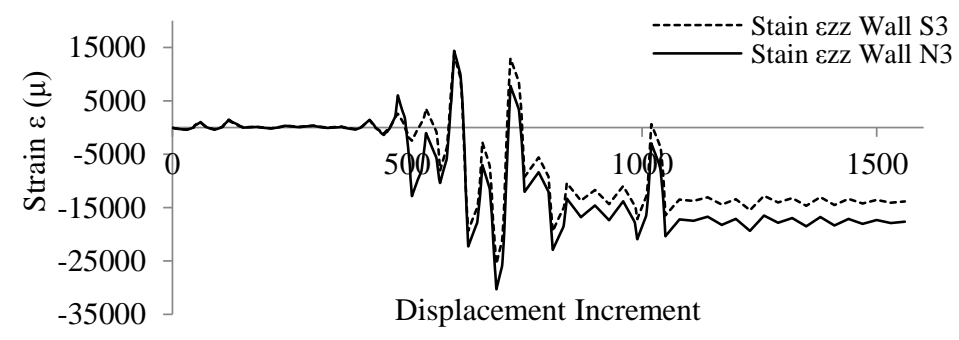

Fig. 22. $2^{\text {nd }}$ loading test $(0.25 \mathrm{~g})$. Numerically computed strain $\varepsilon_{\mathrm{z}}$ history at the points $\mathrm{N} 3$ and $\mathrm{S} 3$.

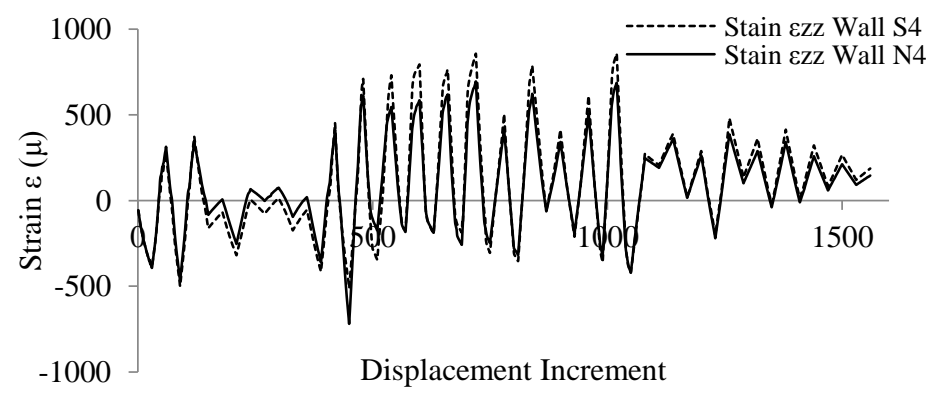

Fig. $23.2^{\text {nd }}$ loading test $(0.25 \mathrm{~g})$. Numerically computed strain $\varepsilon_{\mathrm{z}}$ history at the points $\mathrm{N} 4$ and S4.

The numerically derived strain history diagrams can be seen in Figs. 20-23, where it is evident that for all cases the locations that were chosen to be on the South frame exhibit a higher deformation at a local level. It is also characteristic that the strain at point S2 (Fig. 21) for the displacement increment $690\left(\delta_{\mathrm{H}}=-92 \mathrm{~mm}\right)$, a larger deformation value equal to $0.68 \%$ resulted, which is much higher than the one obtained at the North frame (N2). This is attributed to the longitudinal rebars yielding within the column of the South frame, which was found to exhibit a more flexible mechanical behavior thus resulted higher damages at the local level (this numerical finding also complies with the experimental observations reported in Martin et al. 2013). This mechanical phenomenon, which also was captured through the analysis performed herein, is attributed to the lower reinforcement ratio that was used to reinforce the RC infill walls located at the South $\mathrm{RC}$ frame.

Figs. 22 and 23, illustrate the strains at the S3-N3 and S4-N4 locations, as they resulted for the numerical analysis of the model. The numerical findings indicate that the $\mathrm{RC}$ domains that are located outside the CFRP confined region had a more flexible response developing larger deformations in comparison to the RC locations (S4-N4) that were confined. Based on the two graphs, it is easy to conclude that the unconfined locations developed large deformation that lead to significant cracking (due to the shifting of the plastic hinge). The maximum computed $\varepsilon_{\mathrm{zz}}$ strain deformation at $\mathrm{S} 4$ was $857 \times 10^{-6}$, which was $15 \%$ higher that the corresponding magnitude computed at N4. Furthermore, the corresponding deformations at S3 and N3, where found to be significantly higher due to the rebar yielding that occurred within these locations.

The remaining von Mises deformation can be also depicted in Figs. 20-23 (final displacement step 1,560), due to the accumulated damage at both materials (concrete and rebars) during the cyclic analysis. Furthermore, after the completion of the $2^{\text {nd }}$ loading test, the deformed shapes and the von Mises strain contours were visualized and illustrated in Fig. 24. It is evident that the remaining strains are larger compared to those obtained from the $0.1 \mathrm{~g}$ test, given that the imposed horizontal deformations were almost 5 times larger during the $2^{\text {nd }}$ test. The numerically predicted areas that derived higher damages were found to be at the column-beam joints and the $\mathrm{RC}$ walls, where the shear 
deformation was found to be excessive. This also complies with the experimental findings.

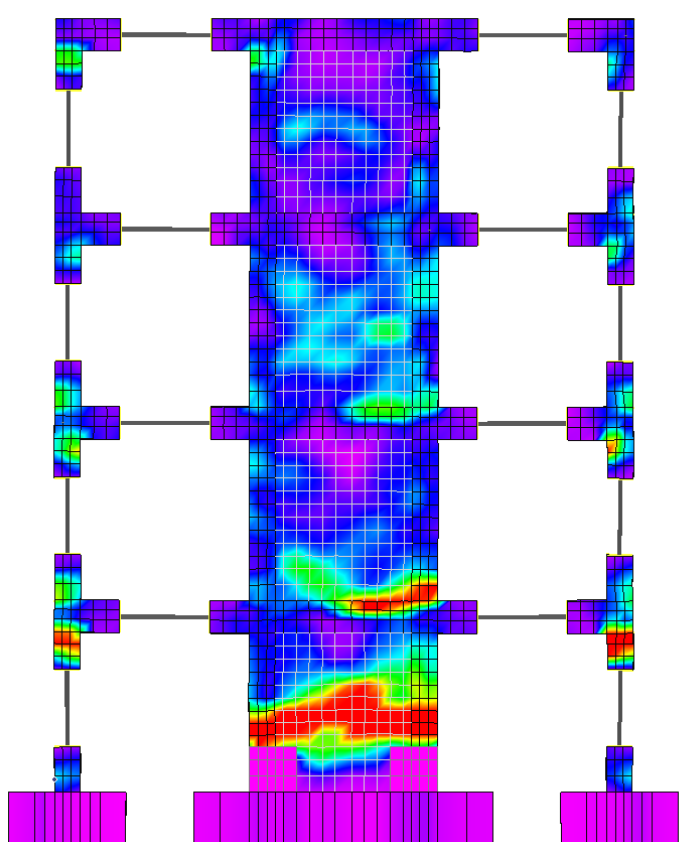

a. South Frame

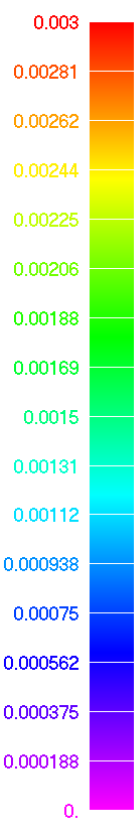

0.

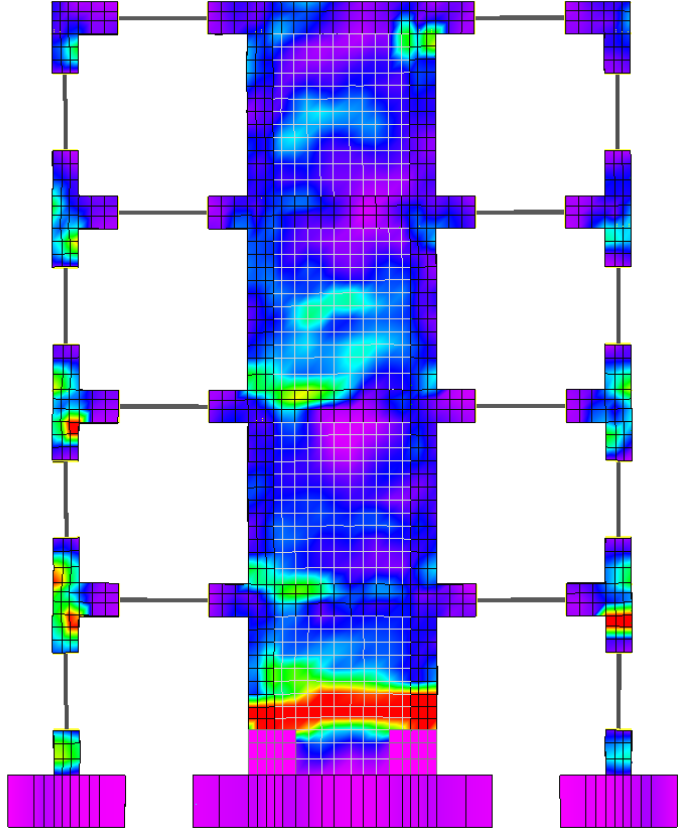

b. North Frame

Fig. 24. $2^{\text {nd }}$ loading test $(0.25 \mathrm{~g})$. Remaining von Mises strain contour after the completion of the test (displacement increment 1,$560 ; \delta_{\mathrm{H}}=0 \mathrm{~mm}$ ). Deformation magnification factor $\mathrm{x} 20$.

In regards to the computational details related to the $2^{\text {nd }}$ numerical analysis, Table 3 shows the required time for the solution of 1,560 displacement increments and 7,504 internal iterations. The total computational time for the nonlinear analysis was 29 hours and 28 minutes, which corresponds to a 14.14 seconds per internal iteration. The average internal iteration per displacement increment was found to be equal to 4.81 and the average numerical error was equal to $8.92 \times 10^{-6}$. According to these numerical results, it is easy to conclude that this numerical problem resulted a smaller average internal iterations per displacement increment and a higher accuracy in terms of the derived error when compared with the obtained results from the $0.1 \mathrm{~g}$ test. This numerical finding is attributed to the smaller displacement increment that was used during the nonlinear analysis procedure, even though the numerical nonlinearities that were developed during the analysis were significantly higher (cracking and rebar yielding). This is also an additional evidence of the numerical robustness of the HYMOD algorithm in handling extreme nonlinearities.

Table 3 Computational performance of the algorithm for the case of the $0.25 \mathrm{~g}$ test.

\begin{tabular}{|c|c|c|c|c|c|}
\hline $\begin{array}{c}\text { Total Displ } \\
\text { Incr. Solved }\end{array}$ & $\begin{array}{c}\text { Total } \\
\text { Internal } \\
\text { Iter. }\end{array}$ & $\begin{array}{c}\text { Average } \\
\text { Numerical } \\
\text { Error }\end{array}$ & $\begin{array}{c}\text { CPU Time } \\
\text { Nonlinear Solution } \\
\text { (hours) }\end{array}$ & $\begin{array}{c}\text { Other CPU Time } \\
\text { (hours) }\end{array}$ & $\begin{array}{c}\text { Size of the Output File } \\
(\mathrm{Gb})\end{array}$ \\
\hline 1,560 & 7,504 & $8.92 \times 10^{-6}$ & 29.46 & 2.7 & 70.8 \\
\hline
\end{tabular}

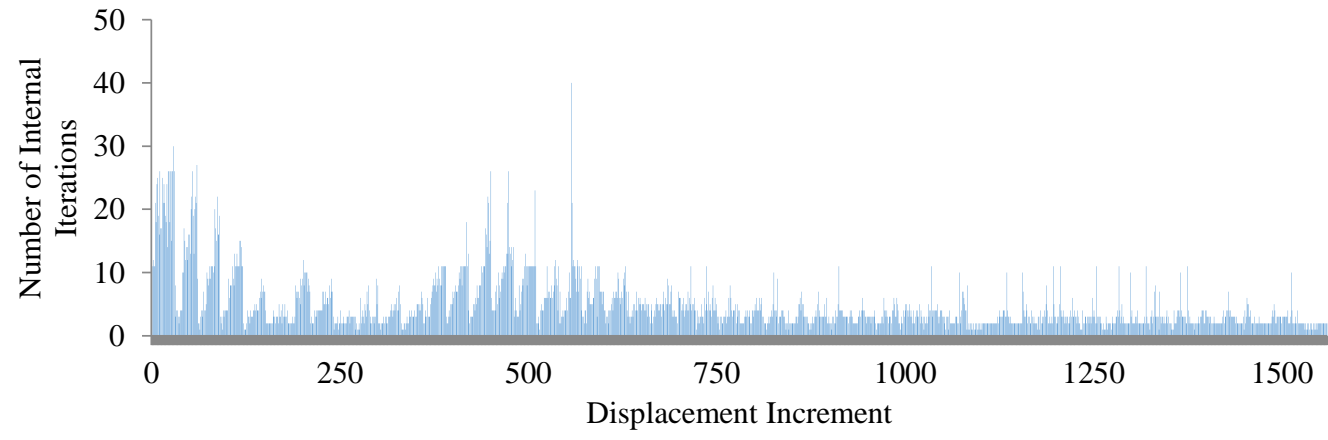

Fig. 25. $2^{\text {nd }}$ loading test $(0.25 \mathrm{~g})$. Number of internal iterations vs displacement increment.

The total required hard disk space in order to save the output file for this run was $70.8 \mathrm{~Gb}$, which once more highlights the significance of engaging the HYMOD approach and the ability to solve this type of problems through the use of commercial PC systems. Fig. 25 shows the graph that contains 
the corresponding number of internal iterations per displacement increment. According to this graph, it was found that $68.5 \%(1,069)$ of the displacement increments required less than 5 internal iterations to reach convergence, $88.2 \%(1,376)$ required less than 10 and only a mere $1.9 \%(30)$ of the displacement increments required more than 20 internal iterations so as to achieve convergence. This is a numerical response that further demonstrates the robustness and the numerical stability of the developed algorithm.

\subsection{Analysis Results for the Final Loading Test}

The final displacement test ("funeral cycles" Martin et al. 2013), foresaw the application of 2.5 displacement cycles (Fig. 8c) in an attempt to push the RC frame to reach its maximum capacity. As it was stated before, the frame was pushed and at the same time the corresponding base shear was measured (Kyriakides et al. 2015) waiting to notice a sudden drop in terms of resistance. According to the experimental measurements, the frame was then considered to have reach its maximum capacity. For the needs of this final analysis, the undamaged model was used once more so as to simulate the mechanical behavior of the RC frame when it undergoes the "funeral cycles" displacement history test.

Fig. 26 shows the comparison between the numerical and the experimental results, where it is evident that the computed initial stiffness from the numerical model is significantly higher than the one measured during the experiment (Martin et al. 2013), given that the HYMOD foresaw the use of the undamaged model at the beginning of the analysis. Both positive and negative maximum base shear capacities were overestimated herein, a numerical finding that was expected, given that this modeling strategy is not realistic as it was discussed and explained in section 5.3. In order to establish a more realistic modeling strategy, a second analysis was performed by assuming a displacement history combination (Combo 1) that foresaw the use of a preparatory displacement history that consisted of 4 loading cycles (see Fig. 27), where at the end of this displacement history the "funeral cycles" were imposed based on the experimental data. The preparatory cycles were developed by using the maximum positive and negative horizontal displacements that were developed in the two previous loading tests $(0.1 \mathrm{~g}$ and $0.25 \mathrm{~g})$.

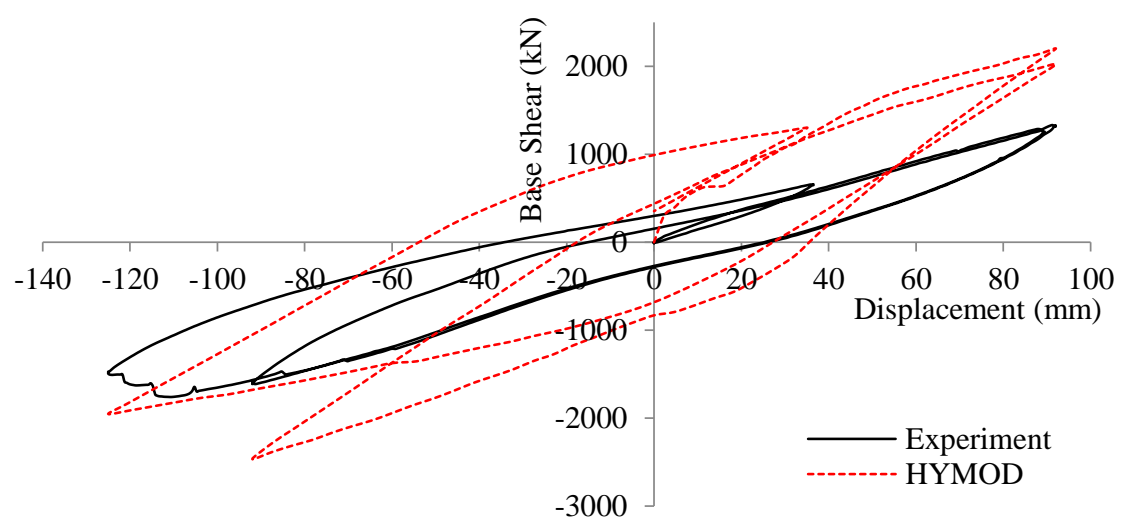

Fig. 26. $3^{\text {rd }}$ loading test ("funeral cycles"). Experimental vs numerical curves. Total base shear-horizontal displacement of the top floor. Undamaged model.

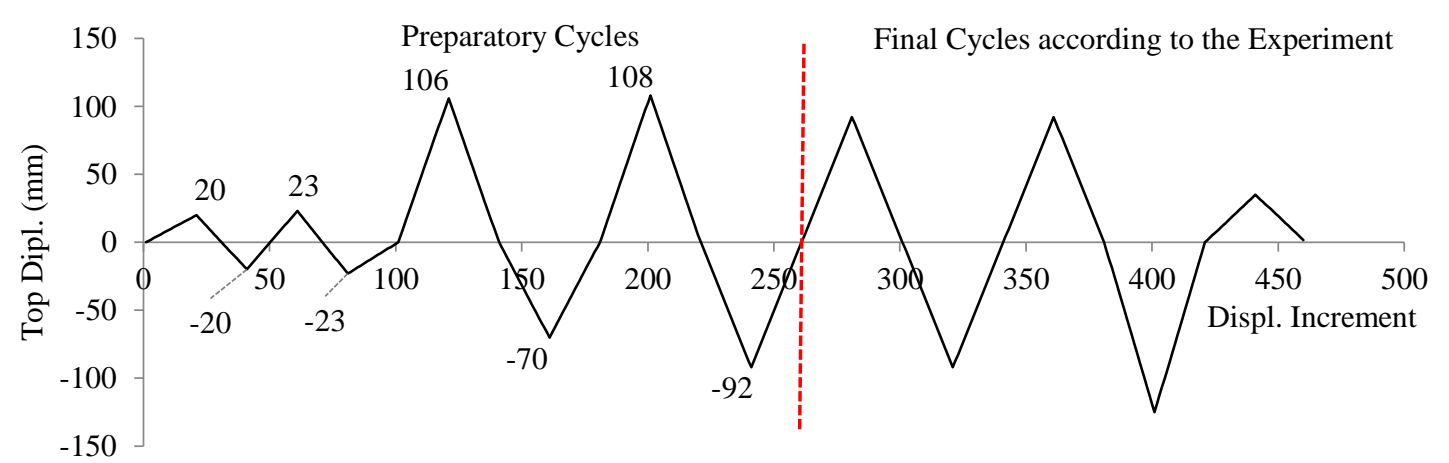

Fig. 27. Combo 1 displacement history applied at the top floor of the specimen. 


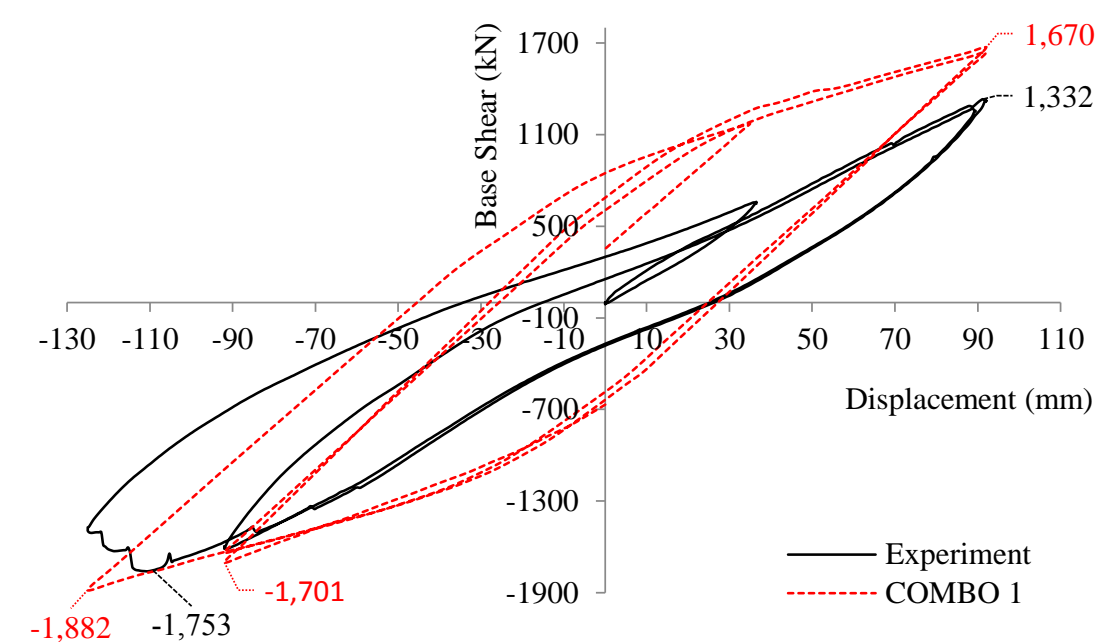

Fig. 28. $3^{\text {rd }}$ loading test ("funeral cycles"). Experimental vs numerical curves. Total base shear-horizontal displacement of the top floor. Combo 1 displacement history.

Fig. 28 shows the corresponding comparison of the numerical and experimental curves for the case of the Combo 1 displacement history (Fig. 27). As it can be seen, the base shear drop for the numerically predicted capacity of both negative and positive maxima imposed displacements is evident, thus demonstrates the numerical ability of the algorithm in capturing the structure's deterioration due to the multiple cyclic deformations. The newly computed total base shear was found to decrease to $1,701 \mathrm{kN}$ (negative displacement $92 \mathrm{~mm}$ ), which was $3.5 \%$ larger than the experimental value $(1,670 \mathrm{kN})$. Furthermore, the base shear for the case of the maximum negative displacement (125 mm) was computed to be equal to $1,882 \mathrm{kN}$, while the corresponding experimentally obtained value was $1,753 \mathrm{kN}$. Based on these new resistance values, the numerical prediction is $7.4 \%$ higher than the experimental one, a numerical phenomenon that can be also observed for the shear base values that were computed for the positive deformations (the two positive horizontal displacements of 92 $\mathrm{mm}$ ). Based on the new numerical findings, it was concluded that there was the need of performing an additional analysis by using a refined preparatory displacement history so as to further take into account the damages occurred during tests 1 and 2, in a more realistic manner.

In order to improve the numerical prediction thus capture the experimental curve through a more realistic displacement history, a $3^{\text {rd }}$ displacement history (Combo 2) was developed herein that foresaw the use of 7 preparatory displacement cycles. As it can be seen in Fig. 29, the cycles foresaw the application of horizontal displacements that varied between 108 and $-92 \mathrm{~mm}$. A total of 825 displacement increments were used in order to analyze this highly nonlinear numerical problem.

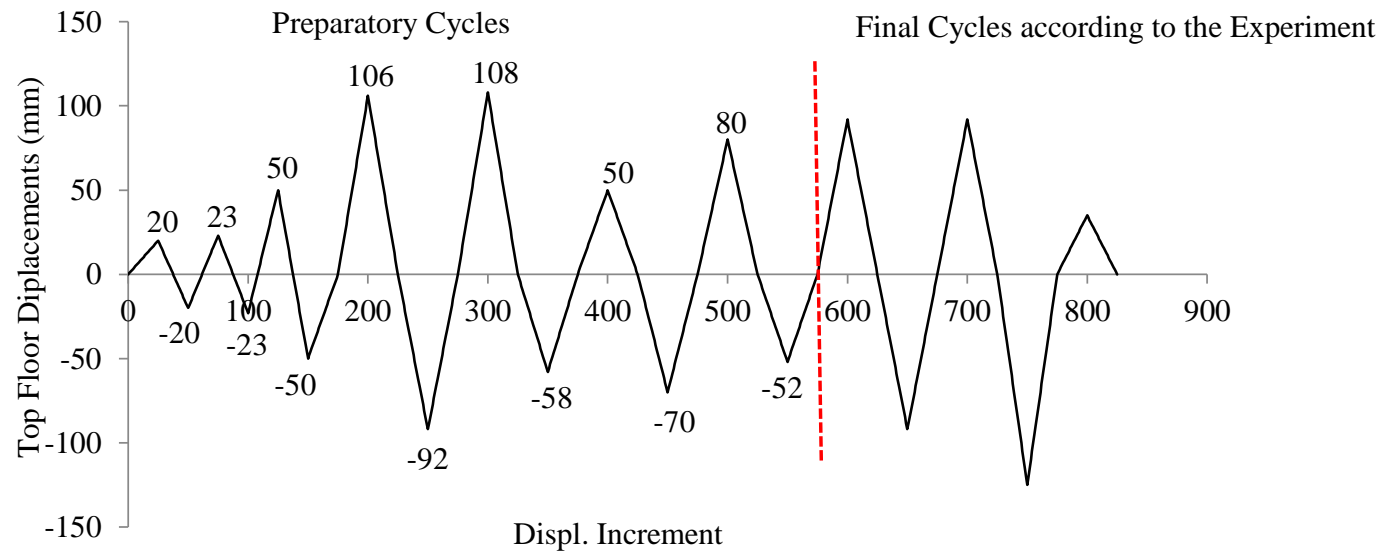

Fig. 29. Combo 2 displacement history applied at the top floor of the specimen.

Fig. 30 shows the comparison between the experimentally and numerically derived curves for the case of the Combo 2 displacement history, where it can be easily observed that the numerical trend described above, related to the capacity decrease, is confirmed through this additional simulation. Therefore, the larger the number of the preparatory cycles is, the higher the decrease of the maximum predicted base shear gets due to the concrete material deterioration (more cracks open and fail to close during the analysis). The difference between the predicted maximum negative base shear is less than 
$2 \%$ in the cases of -92 and $-125 \mathrm{~mm}$ horizontal displacements, as depicted in Fig. 30. The maximum base shear for the case of the positive horizontal displacements are still higher than the experimental ones due to the numerical phenomenon that relates to the damage that accumulates in both concrete and steel materials.

In addition to that, it is also easy to observe that the numerically predicted hysteretic loops are larger in comparison to the experimentally obtained ones, which is a phenomenon that can be attributed to the small number of preparatory displacement cycles that were solved prior to the last set of displacement history test (Fig. 29) and the lack of a damage factor that will further decrease the material strength due to the multiple opening and closing of cracks. The use of damage factors in this case could help in capturing the degradation of concrete in a more realistic manner thus fortify the model in capturing more complicated phenomena such as the pitching effect. For this reason, the concrete and steel material formulations are being currently integrated with two new damage factors that will be able to account for this phenomenon based on how many times a crack has opened and closed. This will be the subject of a future publication.

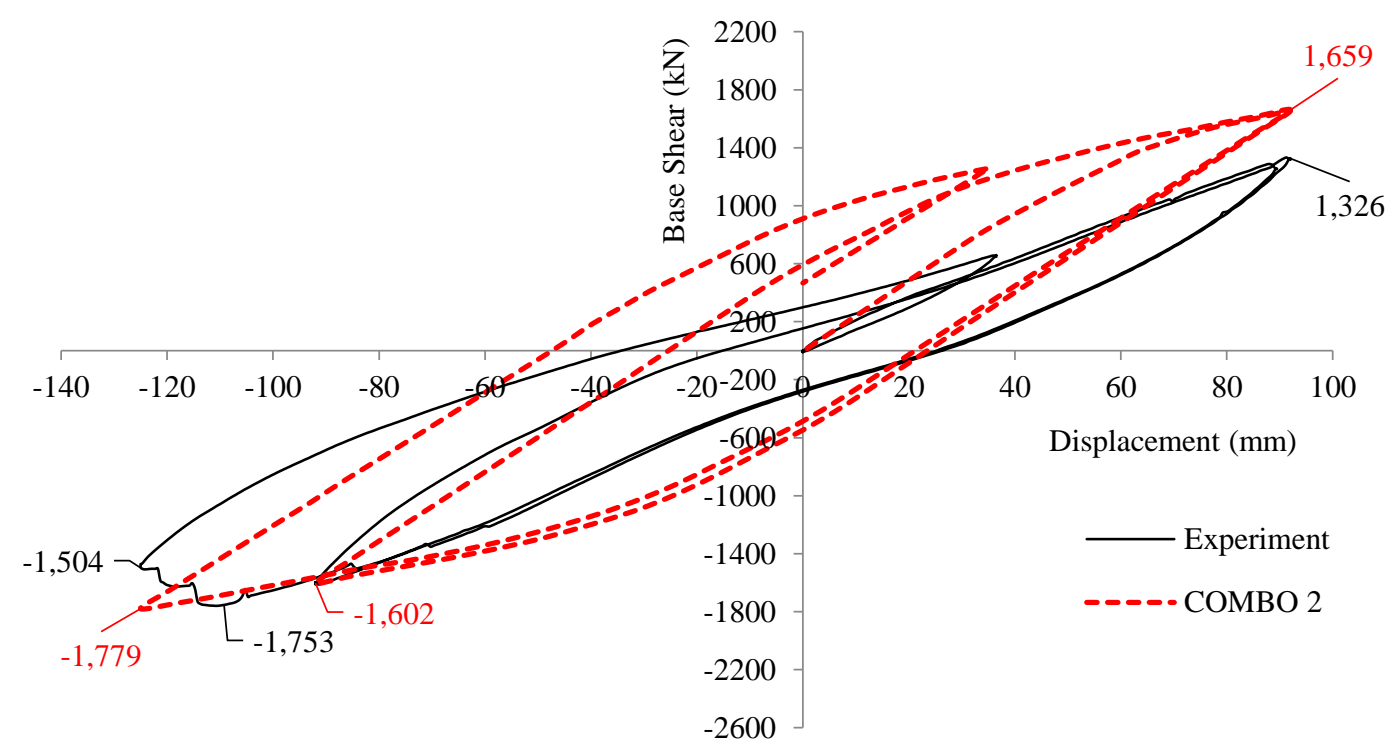

Fig. 30. $3^{\text {rd }}$ loading test ("funeral cycles"). Experimental vs numerical curves. Total base shear-horizontal displacement of the top floor. Combo 2 displacement history.

To further elaborate on the higher computed capacity for the case of the positive horizontal displacements, it must be reminded at this point that the actual experiment foresaw the cyclic loading of the building according to the loading history tests of $0.1 \mathrm{~g}$ and $0.25 \mathrm{~g}$. The damage that had accumulated at the concrete and steel materials within the two frames is a factor that cannot be ignored when attempting to model the funeral cycles. This should also be the case when modeling the RC building, but for the computational-related reasons that were explained above this was not feasible. Nevertheless, a final analysis was performed so as to show the ability of the model to capture the experimental data, by modifying the material properties of concrete and steel. This is a numerical approach that is broadly acceptable and extensively used (in order to account for the existing damage). Nonetheless, this is not considered by the authors to be numerically objective given that the assumptions that are made in defining the new material values do not follow a specific set of rules but are based on the experience of the user. Therefore, in the case of the RC retrofitted building, the steel material hardening modulus was set to $20 \mathrm{MPa}$ for all embedded rebar properties except for that of the $20 \mathrm{~mm}$ rebar element that was set to 0 . The reasoning behind this approach, of applying a maximum decrease on the hardening modulus of the $20 \mathrm{~mm}$ rebars, was the fact that these reinforcement are located at the areas that sustained significant damages during the two first test. Especially at the columns and the boundary elements of the RC shear walls located at the ground floor, structural members that were reinforced with $20 \mathrm{~mm}$ in diameter rebars. The concrete material model was also modified by decreasing its tensile strength from $5 \%$ to $3 \%$, while the same displacement history was used in performing the cyclic analysis (see Fig. 29). 


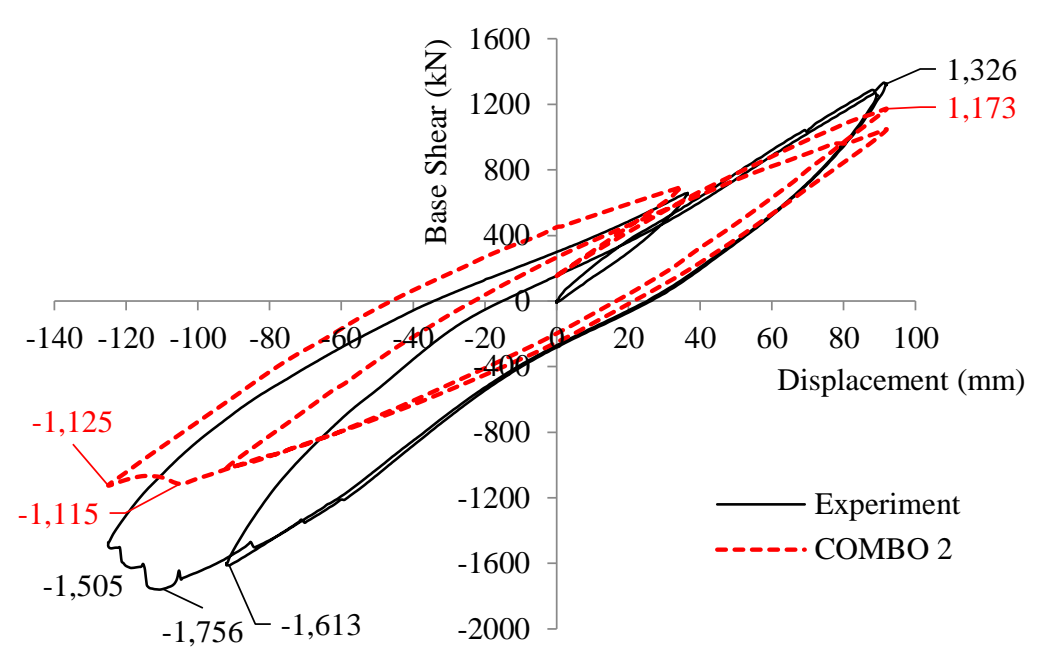

Fig. 31. $3^{\text {rd }}$ loading test (“funeral cycles"). Experimental vs numerical curves. Total base shear-horizontal displacement of the top floor. Model with modified material properties. Combo 2 displacement history.

Fig. 31 shows the comparison between the experimental and numerical results, where it can be easily observed that the numerically derived capacity has decreased significantly due to the material modifications. The maximum computed resistance of the building for the positive horizontal displacement was $1,173 \mathrm{kN}$, which corresponds to a $11.5 \%$ accuracy in favor of safety. On the other hand, the decrease of the numerically predicted maximum negative capacity was higher due to the rebar failures that occurred when the model was pushed to reach the $-125 \mathrm{~mm}$ horizontal displacement. This numerical response is attributed to the low hardening modulus that was used, which resulted into larger local deformations at the rebars located in the columns and shear walls of the ground floor. Based on the parametric investigation performed herein, it was concluded that the drop in-terms of strength and energy dissipation was attributed to the hardening modulus decrease given that during the third and final displacement history test the embedded rebars located at the beam-column joints and the boundary elements of the shear walls were plastified thus the hardening modulus was controlling their mechanical behavior.

An additional conclusion that derives from this final analysis is that, when trying to predict the carrying capacity of any specimen or real structure, the greatest modeling challenge is the selection of the material property values for both steel and concrete. In the case where these values are available from material tests (Martin et al. 2013), then the ability of the numerical model used in predicting the structural capacity by using the exact material property values, is of great significance given that this numerical ability will eventually minimize the need of additional assumptions during the construction of the model and especially during the definition of the material model parameters. This numerical finding also demonstrates the inability of the simplified numerical models (Kyriakides et al. 2015) to be considered as adequate in the case where the assessment of an existing damaged $\mathrm{RC}$ building is required, in an attempt to predict its current capacity.

Table 4 shows the computational performance data for the solution of the 3 analyses performed so as to simulate the funeral cycles. For the three analyses, the average error was calculated and found to be equal to $2.29,1.07$ and $1.28 \times 10^{-5}$, respectively. Figs. 32-34 show the graphs of the corresponding internal iterations per displacement increment, as they resulted from the three analyses. It is evident that the low ratio of internal iterations per displacement increment trend is present, therefore, this numerical finding further supports the previous statement in regards to the HYMOD's algorithmic robustness and numerical stability. The average ratios of internal iterations per displacement increment for the case of these three analyses were $8.28,6.84$ and 5.67, respectively.

Table 4 Computational performance of the Funeral and Combo Final cycle analyses.

\begin{tabular}{|c|c|c|c|c|c|}
\hline a/a & Displ. Function & $\begin{array}{c}\text { Total Displacement } \\
\text { Increments Solved }\end{array}$ & $\begin{array}{c}\text { Total } \\
\text { Internal } \\
\text { Iterations }\end{array}$ & $\begin{array}{c}\text { Average Numerical } \\
\text { Error }\end{array}$ & $\begin{array}{c}\text { CPU Time } \\
\text { Nonlinear Solution } \\
\text { (hours) }\end{array}$ \\
\hline 1 & Funeral cycles & 240 & 1,988 & $2.29 \times 10^{-5}$ & 7.81 \\
\hline 2 & Combo 1 & 460 & 3,146 & $1.07 \times 10^{-5}$ & 12.37 \\
\hline 3 & Combo 2 & 825 & 4,676 & $1.28 \times 10^{-5}$ & 18.39 \\
\hline
\end{tabular}




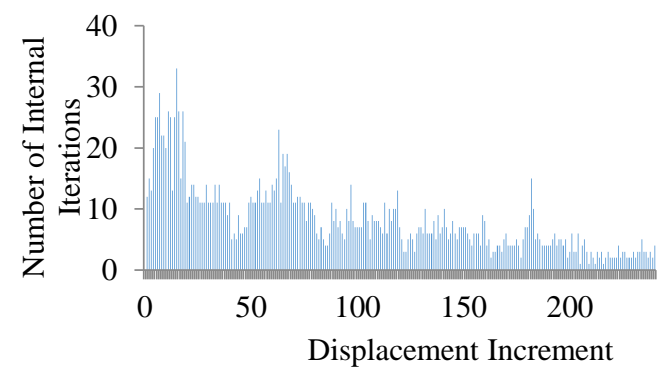

Fig. 32. $3^{\text {rd }}$ loading test ("funeral cycles"). Number of internal iterations vs displacement increment. Undamaged model.

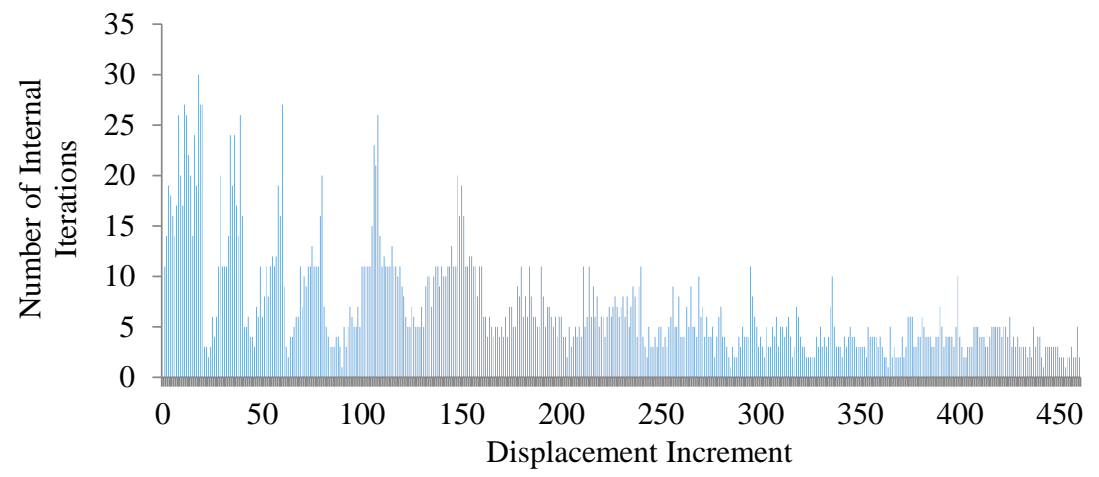

Fig. 33. $3^{\text {rd }}$ loading test (“funeral cycles"). Number of internal iterations vs displacement increment. Combo 1 displacement history.

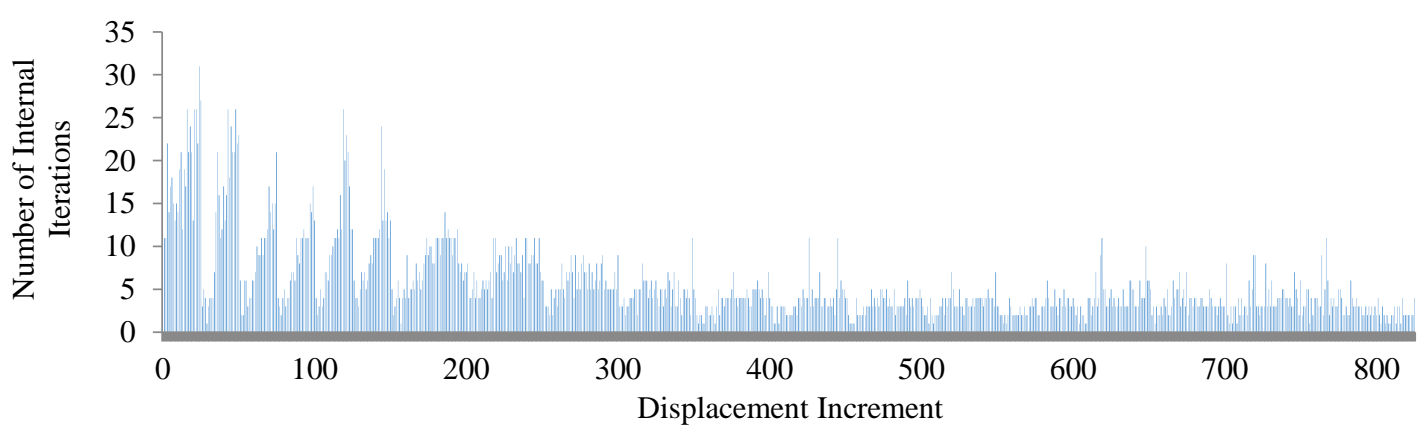

Fig. 34. $3^{\text {rd }}$ loading test (“funeral cycles"). Number of internal iterations vs displacement increment. Combo 2 displacement history.

\subsection{Numerical Investigation of Different Infill RC Wall Retrofitting Configurations}

The introduction of new infill RC walls within an existing framing system increase significantly the stiffness and the carrying capacity of any multistory RC building, but it can also affect its overall mechanical response that can lead to local failures during an earthquake excitation, a mechanical response that might not be anticipated by the designers. In order to further examine the effect on the mechanical behavior of RC structures when a frame is retrofitted with infill RC walls, the 4-storey building without infill walls is initially examined in this section through the use of the model illustrated in Fig. 35. The displacement history depicted in Fig. 29 was applied in this case in order to compare the numerically predicted capacity of the bare frame and compute the actual strength enhancement induced to the framing system due to the introduction of the infill $\mathrm{RC}$ walls, as it was studied and presented above.

In Fig. 36, the force-displacement curves for the "funeral cycles" (last loading cycles of the graph given in Fig. 29) are compared for the case of the fully retrofitted and the bare frames. As it derives from the numerical investigation, the infill RC walls significantly increase the stiffness of the building's frame, while the capacity of the building increases accordingly as well. Therefore, the shear capacity of the building is significantly larger as it can be observed in Fig. 36, where the hysteretic cycles of the retrofitted frame are notably larger. Based on the obtained numerical results that are given in Table 5, the structure with the infilled RC walls presents a $155.6 \%, 159.5 \%$ and $223.3 \%$ larger shear capacity for the positive maximum deformations and, a $209.6 \%$ and $194.9 \%$ larger shear capacity for the respective maximum negative deformations of the imposed displacement history. This numerical finding demonstrates that the design of the infill $\mathrm{RC}$ walls manages to increase the shear capacity more 


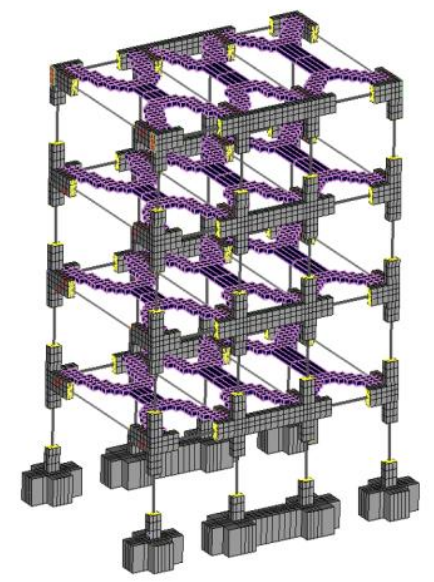

Fig. 35. 3D view of the hexahedral HYMOD mesh of the bare frame.

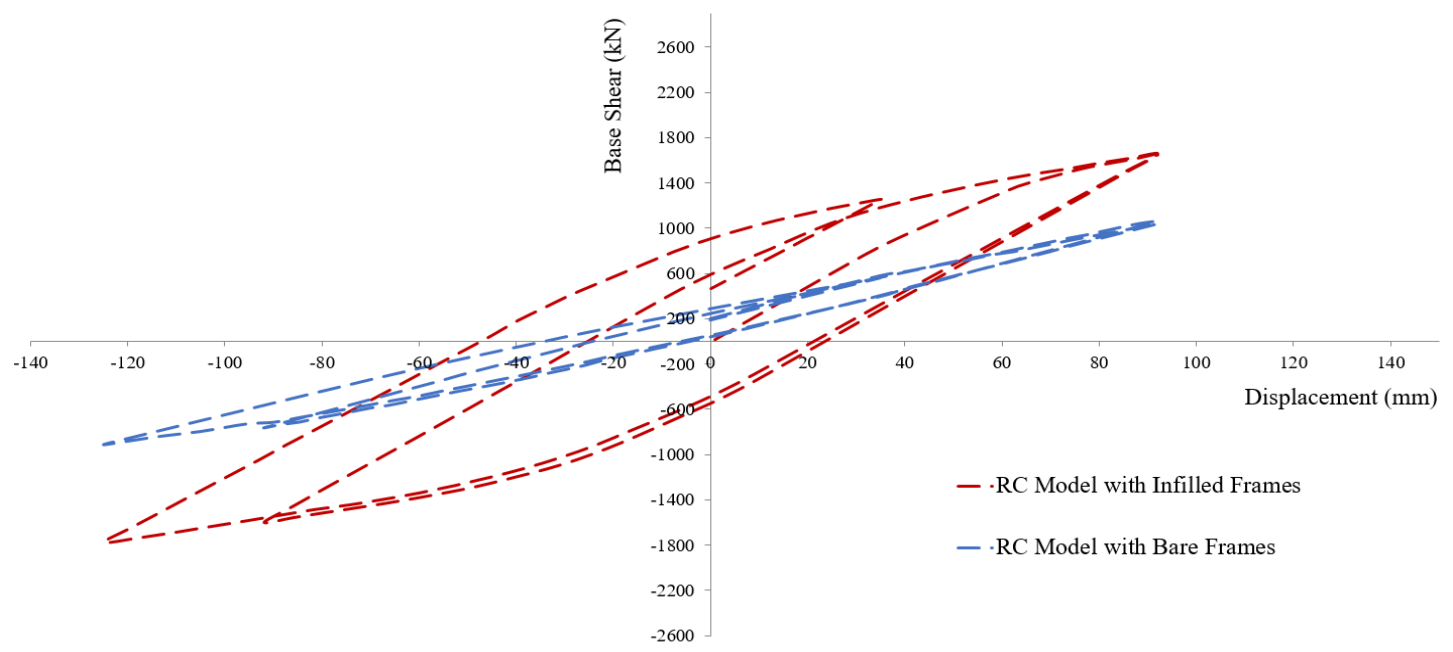

Fig. 36. Loading test (“funeral cycles"). RC Model with bare frame vs infilled RC walls. Total base shear-horizontal displacement of the top floor.

Table 5 Base shear comparison between the RC model with infill shear wall and without shear wall

\begin{tabular}{|c|c|c|c|c|c|c|c|}
\hline \multicolumn{2}{|c|}{$\begin{array}{c}\text { Displacements } \\
(\mathrm{mm})\end{array}$} & \multicolumn{2}{c|}{$\begin{array}{c}\text { Max Base Shear of } \\
\text { RC Model with Bare } \\
\text { Frames-BF } \\
(\mathrm{kN})\end{array}$} & $\begin{array}{c}\text { Max Base Shear of } \\
\text { RC Model with } \\
\text { Infilled RC Walls-IF } \\
(\mathrm{kN})\end{array}$ & \begin{tabular}{c}
\multicolumn{2}{c|}{ IF } \\
BF \\
$(\%)$
\end{tabular} \\
\hline Positive & Negative & Positive & Negative & Positive & Negative & Positive & Negative \\
\hline 92 & -92 & 1062.10 & -764.68 & 1652.25 & -1602.49 & 155.6 & 209.6 \\
\hline 92 & -125 & 1040.15 & -912.80 & 1659.45 & -1779.49 & 159.5 & 194.9 \\
\hline 35 & 0 & 562.83 & - & 1257.00 & 466.66 & 223.3 & - \\
\hline
\end{tabular}

Furthermore, the ability of the building to absorb energy during an earthquake excitation is significantly affected due to the infill RC walls. As illustrated in Fig. 36, the hysteretic loops of the model with the infill walls are found to be 5 times larger than the corresponding hysteretic loops of the areas of the model with the bare frame. Table 6 shows the numerically computed values of the dissipated areas for the two final loading cycles for the two numerical models, where it can be depicted that the model with the infilled RC walls exhibits a dissipated area which is $439 \%$ larger than that obtained through the model with the bare frame (for the case of the $2^{\text {nd }}$ loading cycle). Therefore, the infill RC walls are found to induce a significant increase of the energy dissipation level of the structure as compared to the corresponding mechanical response derived from the bare frame. Based on the numerical study performed herein, it was concluded that as the excessive strains and stresses are developed within the RC shear walls, their presence ensures a sufficient and reliable mechanical 
system that is capable to dissipate energy, which is caused by extreme cyclic loading conditions. This finding further demonstrates the overall contribution of the infill $\mathrm{RC}$ walls in terms of earthquake resistance from a qualitative and quantitative perspective.

Table 6 Dissipated energy comparison between the RC model with infill shear wall and without shear wall

\begin{tabular}{|c|c|c|c|}
\hline Dissipated Energy & $\begin{array}{c}\text { RC Model with } \\
\text { Bare Frames -BF } \\
(\mathrm{kN} \mathrm{mm})\end{array}$ & $\begin{array}{c}\text { RC Model with } \\
\text { Infilled Frames-IF } \\
(\mathrm{kN} \mathrm{mm})\end{array}$ & $\begin{array}{c}\frac{\mathbf{I F}}{\mathbf{B F}} \\
(\%)\end{array}$ \\
\hline $1^{\text {st }}$ Cycle & $23,758.14$ & $104,391.98$ & 439.4 \\
\hline $2^{\text {nd }}$ Cycle & $35,018.48$ & $175,570.06$ & 501.4 \\
\hline
\end{tabular}

In order to further investigate the efficiency of the infill RC wall intervention method, two new retrofitting configurations were examined and presented in this section. The two additional models that were developed by using the fully retrofitted HYMOD model shown in Fig. 10, foresee the use of infill RC walls at the ground floor (Fig. 37a) and, at the ground and first floors (Fig. 37b), respectively. The finite element meshes of the two additional models developed for the needs of this numerical investigation can be seen in Fig. 37. As a first stage of this numerical experiment, the displacement history shown in Fig. 29 was applied to numerically obtain the maximum carrying capacity and study the overall mechanical response of the two new retrofitted frames. Both frames did not manage to deform beyond a certain displacement limit (due to tensile rebar failures that led to the termination of the nonlinear analyses) thus the displacement history had to be modified accordingly so as to achieve a complete analysis solution for both models. According to the initial run, the first retrofitting model (Fig. 37a) derived a failure prior to reaching the maximum negative horizontal displacement (125 mm) thus the corresponding magnitude was decrease to $110 \mathrm{~mm}$, hence manage performing the complete analysis without reaching a premature failure. For the case of the second retrofitting model (Fig. 37b), it was found that a failure during the first maximum positive displacement of the funeral cycles (92 $\mathrm{mm}$ ) occured, thus both positive and negative maximum displacement magnitudes of the funeral cycles were decreased to 80 and $100 \mathrm{~mm}$, respectively.

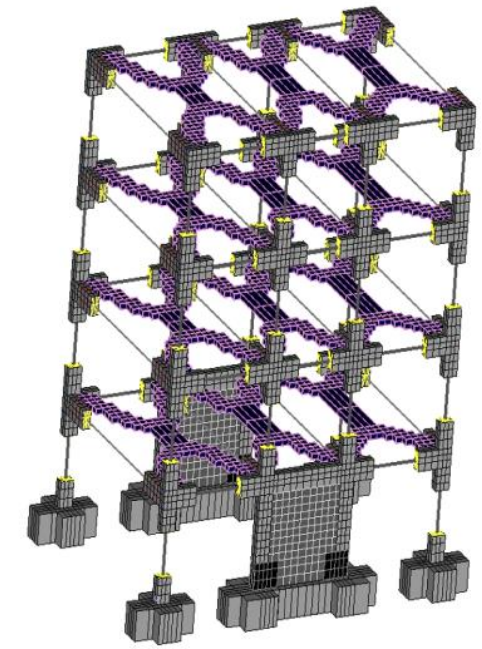

(a)

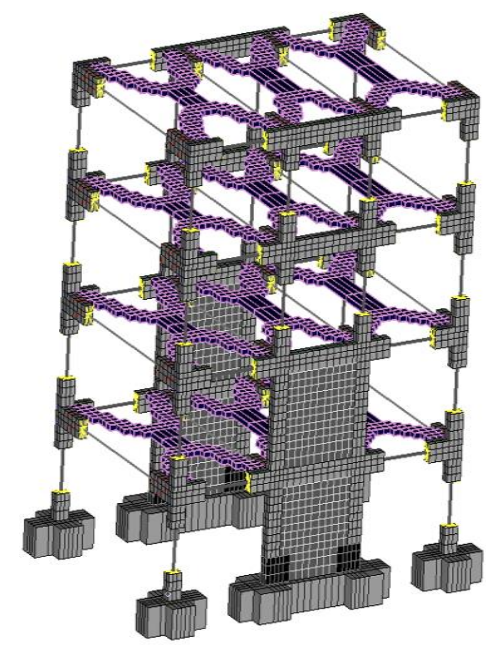

(b)

Fig. 37. 3D mesh view of the 4-storey RC building with infill RC walls at the (a) ground floor and (b) ground and first floors.

Fig. 38 shows the comparison of the numerically predicted curves between the two different retrofitting models (see Fig. 37). One of the main objectives of this parametric investigation was to examine the overall effect of the different intervention geometries in terms of base shear and energy dissipation enhancement. The obtained numerical results that are shown in Fig. 38, show that the two new models derived an overall base shear capacity that lies between the fully retrofitted and the bare frame models. Therefore, a first finding of this study is that the fully retrofitted frame was found to be the intervention design that derives the largest capacity and energy dissipation enhancement. Nonetheless, it is also the design solution that requires the highest cost so as to be implemented. 
The first retrofitting model (Fig. 37a) was found to be the most flexible out of the three retrofitted models examined in this work, given that it foresaw the use of infill RC walls only at the ground floor. It is interesting to note here that the base-shear capacity of the model with the infill RC walls at the ground and first floors (Fig. 37b) derived a similar shear capacity with that obtained by the first retrofitted model (Fig. 37a). This is attributed to the local failures that were developed in the case of the second retrofitted model, which forced the use of smaller maximum positive and negative horizontal displacements during the funeral cycles (as explained above). Therefore, the shear capacity and energy dissipation enhancement achieved by the two new retrofitting designs (see Fig. 37) are found to be affected not only by the geometry of the infill RC walls, but also by the accumulated local damage concentrations that were developed at the non-retrofitted structural members of the RC frame. This accumulated damage development (recorded mainly at the columns that were found at the floors that were not retrofitted) was significantly affected by the stiffness irregularities along the height of the building, which were induced due to the introduction of the infill RC walls at the lower floors of the structure (Fig. 37). This numerical finding further highlights the complexity of the at hand problem when accumulated damage is accounted for during the seismic assessment of retrofitted RC framing systems.

It must be noted at this stage that the above numerical findings resulted through the study of a relatively simple in geometry frame configuration, where the cyclic displacement history and the corresponding deformation profile applied herein were also rather simplistic (compared to the expected deformation shape of a real structure that undergoes an actual seismic excitation). The complexity of this problem increases exponentially when a structure with an irregular geometry is under study thus is designed by a professional civil engineer to be retrofitted through the use of infill RC walls and CFRP jacketing. This highlights the importance of developing, at a first stage, computationally efficient and robust numerical tools, such as the proposed HYMOD approach, in order to provide researchers with the ability to further investigate retrofitting designs and propose rules and recommendations based on accurate numerical studies and not based on semi-empirical knowhow. Thereafter, the next step will be to further evolve this technology and eventually be able to make these numerical tools available to professional civil engineers.

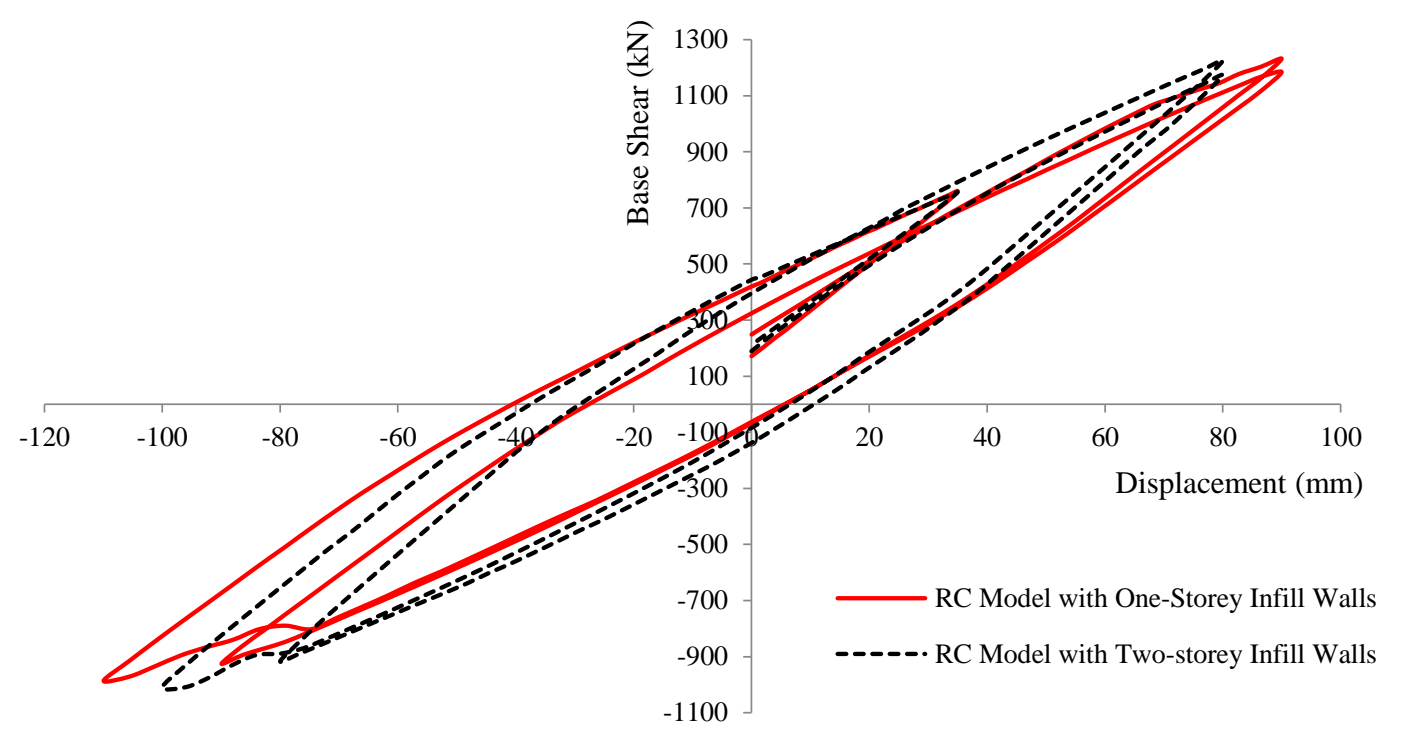

Fig. 38. Loading test (“funeral cycles"). HYMOD Models with different retrofitting configurations. Total base shearhorizontal displacement of the top floor.

In continuation to the above discussion, Table 7 shows the resulted maximum positive and negative base shear capacities of the retrofitted frame as they resulted by analyzing the model in Fig. 37a. The numerically obtained capacities are compared with those resulted by the bare frame model, where it can be seen that the corresponding retrofitted frame (Fig. 37a) manages to increase the base shear capacity for all cycles with the maximum increase being equal to $18.4 \%$ that corresponded to the second funeral cycle's positive maximum horizontal displacement. The computed base shear capacity increase was not as significant as the increase noticed in terms of energy dissipation for the two loading 
cycles, which was computed to be equal to 2.3 and 2 times larger, respectively, compared to those computed by the bare frame model (see Table 9). Equivalent results can be seen in Table 8, where the numerically obtained base shear capacities of the second retrofitted (Fig. 37b) and the bare frames are compared. The comparison in this case shows that the shear capacity of the retrofitted model is increased by $20 \%$ for the case of the first negative maximum horizontal displacement of the $1^{\text {st }}$ loading cycle, whereas the corresponding shear capacity increase is $17.9 \%$ for the second positive maximum positive horizontal displacement.

Based on the computed energy dissipation for the $1^{\text {st }}$ and $2^{\text {nd }}$ loading cycles, the second retrofitted model (Fig. 37b) also managed to increase the frame's energy dissipation capacity by 2.3 and 2 times, respectively (see Table 9). It is noteworthy to state at this point that the ability of the second retrofitted model (Fig. 37b) to deform was limited due to the local accumulated damages developed at the columns of the $3^{\text {rd }}$ floor, thus the maximum horizontal imposed displacements during the funeral cycles were decreased so as for the analysis to complete successfully without any local failures occurring during the last stages of the numerical experiment. This caused the resulted maximum base shear capacities of the second retrofitted frame to remain at a lower than the expected levels (along both the positive and negative $\mathrm{x}$-axis directions).

Additionally, by comparing the maximum resulted base shear capacity obtained from the three retrofitting models, it derives that the two new retrofitting models (Fig. 37) exhibit a 25\% decreased shear capacity compared to the fully retrofitted model, while the corresponding decrease of their energy dissipation in comparison to the fully retrofitted model, is approximately equal to 2.4 times. This highlights the significant increase in terms of energy dissipation when the infill $\mathrm{RC}$ walls are placed throughout the height of the building.

Table 7 Base shear comparison between the RC model with one-storey infill shear walls vs the bare frame model

\begin{tabular}{|c|c|c|c|c|c|c|c|}
\hline \multicolumn{2}{|c|}{$\begin{array}{c}\text { Displacements } \\
(\mathrm{mm})\end{array}$} & \multicolumn{2}{|c|}{$\begin{array}{c}\text { Base Shear of RC } \\
\text { Model with Bare } \\
\text { Frames-BF } \\
(\mathrm{kN})\end{array}$} & $\begin{array}{c}\text { Base Shear of RC } \\
\text { Model with 1-storey } \\
\text { Infilled Frames-IF1 } \\
(\mathrm{kN})\end{array}$ & $\begin{array}{c}\text { IF1 } \\
\text { BF }\end{array}$ \\
\hline Positive & Negative & Positive & Negative & Positive & Negative & Positive & Negative \\
\hline 92 & -92 & 1062.10 & -764.68 & 1184.19 & -925.63 & 111.5 & 121.0 \\
\hline 92 & -110 & 1040.15 & $-912.80^{*}$ & 1232.01 & -986.40 & 118.4 & 108.1 \\
\hline 35 & 0 & 562.83 & - & 760.33 & - & 135.1 & - \\
\hline
\end{tabular}

*Value corresponds to a total of $-125 \mathrm{~mm}$ horizontal displacement.

Table 8 Base shear comparison between the RC model with two-storey infill shear walls vs the bare frame model

\begin{tabular}{|c|c|c|c|c|c|c|c|}
\hline \multicolumn{2}{|c|}{$\begin{array}{c}\text { Displacements } \\
(\mathrm{mm})\end{array}$} & \multicolumn{2}{c|}{$\begin{array}{c}\text { Base Shear of RC } \\
\text { Model with Bare } \\
\text { Frames-BF } \\
(\mathrm{kN})\end{array}$} & $\begin{array}{c}\text { Base Shear of RC } \\
\text { Model with 2-storey } \\
\text { Infilled Frames-IF2 } \\
(\mathrm{kN})\end{array}$ & $\begin{array}{c}\mid c \\
\text { IF2 } \\
(\%)\end{array}$ \\
\hline Positive & Negative & Positive & Negative & Positive & Negative & Positive & Negative \\
\hline 80 & -80 & $1062.10^{* *}$ & $-764.68^{* * *}$ & 1173.92 & -917.34 & 110.5 & 120.0 \\
\hline 80 & -100 & $1040.15^{* *}$ & $-912.80^{*}$ & 1225.85 & -1010.29 & 117.9 & 110.7 \\
\hline 35 & 0 & 562.83 & - & 756.19 & - & 134.4 & - \\
\hline
\end{tabular}

*Value corresponds to a total of $-125 \mathrm{~mm}$ horizontal displacement.

*** Value corresponds to a total of $92 \mathrm{~mm}$ horizontal displacement.

${ }^{* * *}$ Value corresponds to a total of $-92 \mathrm{~mm}$ horizontal displacement.

Table 9 Base shear comparison between the RC model with one- and two-storey infill shear walls vs the bare frame model

\begin{tabular}{|c|c|c|c|c|}
\hline $\begin{array}{c}\text { Dissipated } \\
\text { Energy }\end{array}$ & $\begin{array}{c}\text { RC Model with } \\
\text { 1-Storey Infill } \\
\text { Frames -IF1 } \\
(\mathrm{kN} \mathrm{mm})\end{array}$ & $\begin{array}{c}\frac{\mathbf{I F 1}}{\mathbf{B F}} \\
(\%)\end{array}$ & $\begin{array}{c}\text { RC Model with 2- } \\
\text { Storey Infill } \\
\text { Frames -IF2 } \\
(\mathrm{kN} \mathrm{mm})\end{array}$ & $\begin{array}{c}\frac{\mathbf{B F}}{\mathbf{B F}} \\
(\%)\end{array}$ \\
\hline $1^{\text {st }}$ Cycle & $55,125.10$ & 232.0 & $55,462.42$ & 233.4 \\
\hline $2^{\text {nd }}$ Cycle & $73,358.95$ & 209.5 & $72,575.26$ & 207.2 \\
\hline
\end{tabular}

The deformation shape and the von Mises strain contours are visualized and shown in Figs. 39 and 
40, for the models with the two different retrofitting configurations (Fig. 37). It is easy to observe that the main damages were found to develop at the RC joints and the shear walls of the four frames. It is obvious that the model with infill RC walls placed at the ground floor (Fig. 39) presents larger strain development within the shear walls in comparison to the model with the two-storey shear walls. This is attributed to its ability to deform beyond the limit of $100 \mathrm{~mm}$ horizontal displacement that was the maximum achieved negative $\mathrm{x}$-axis displacement derived by the second retrofitting model (Fig. 40). Furthermore, it can be easily observed that for both models, the south frame seems to suffer from more damages than the north frame, a mechanical behavior attributed to the fact that a lower reinforcement ratio was used based on the design of the South and North infill walls. It must be noted here that, for comparative purposes the von Mises strain contours shown in Figs. 39 and 40, were set to have a maximum strain of $1 \%$. Based on the numerical findings, the maximum predicted von Mises strain was equal to $5 \%$ and $4 \%$ for the first (Fig. 39) and second (Fig. 40) retrofitting models, respectively, whereas the maximum damages were located at the critical areas of the shear walls that are located at the ground floor level in both models and the beam-column joints at the $1^{\text {st }}$ level. In addition to that, the applied deformation profile (which was based on the corresponding experimental data) was found to cause the models to develop significant damages at the $3^{\text {rd }}$ level's columns, attributed to the relative imposed horizontal deformations.
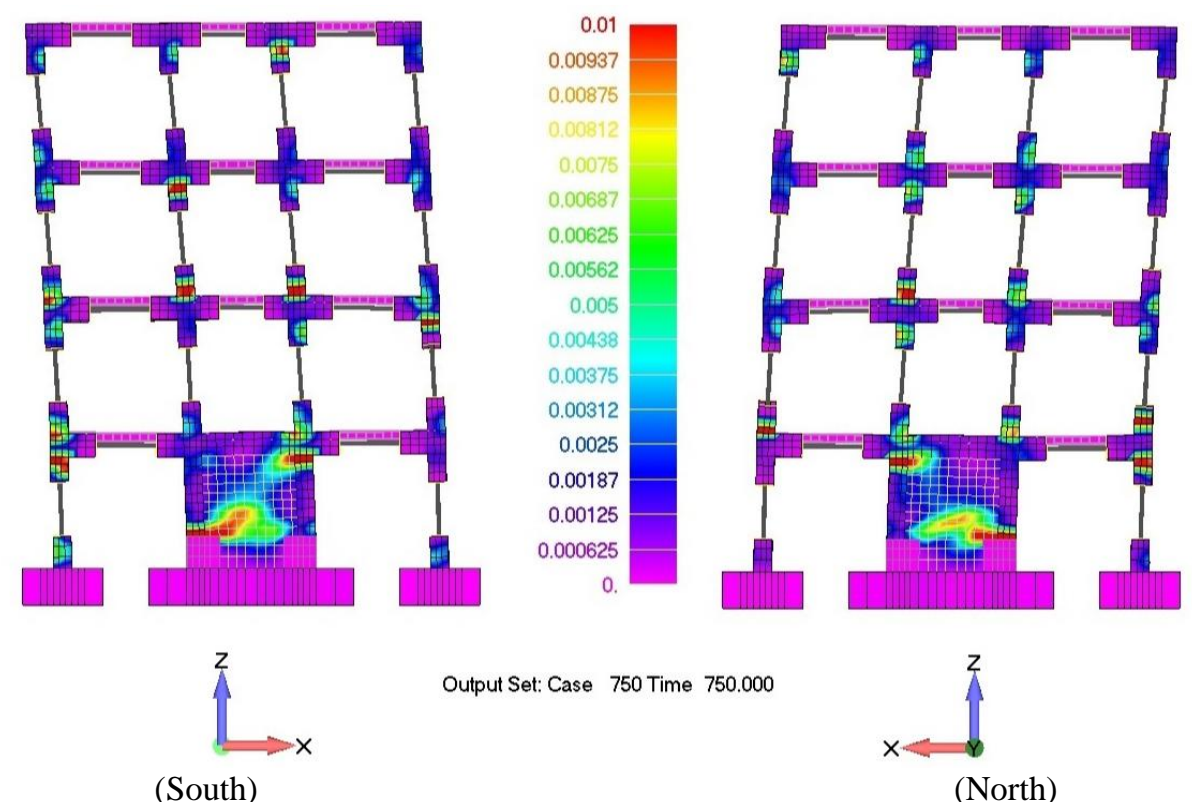

(North)

Fig. 39. One-Storey infill RC walls model. Von Mises stain contour for displacement increment $750\left(\delta_{\mathrm{H}}=-110 \mathrm{~mm}\right)$.

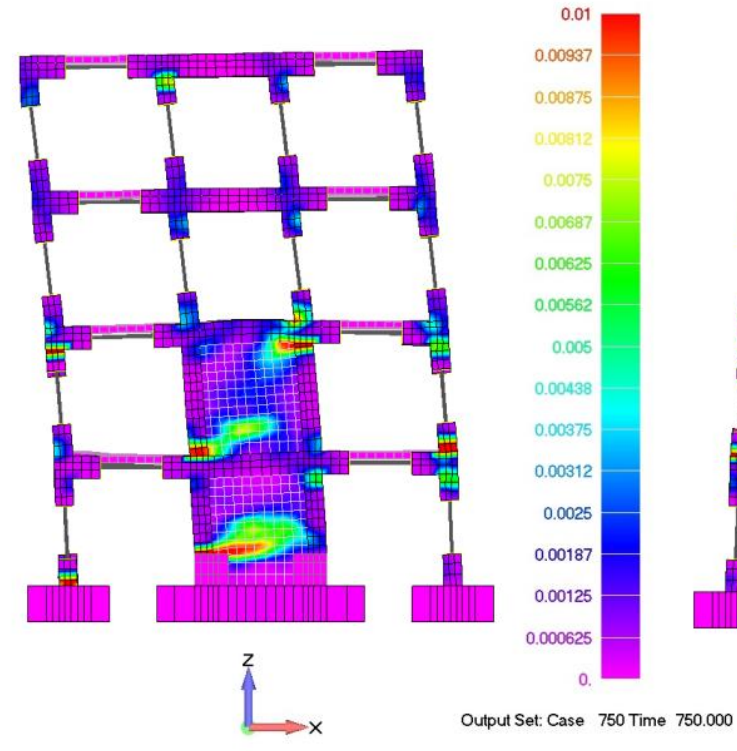

(South)

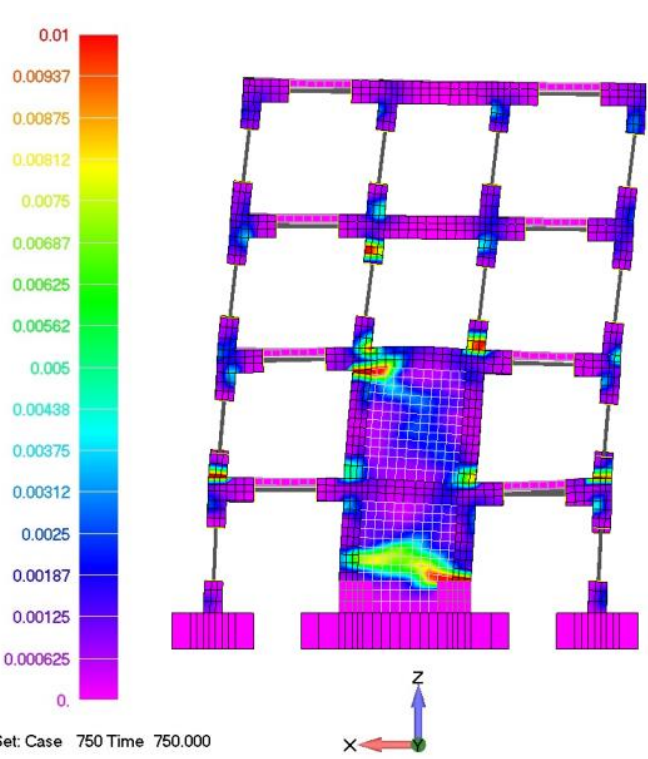

(North)

Fig. 40. Two-Storey infill RC walls model. Von Mises stain contour for displacement increment $750\left(\delta_{\mathrm{H}}=-100 \mathrm{~mm}\right)$. 
In order to further study the mechanical response of the four HYMOD models, a modal analysis algorithm was developed and applied herein for the first time in the international literature (modal analysis of HYMOD meshes) aiming to compute the fundamental periods and frequencies of the under study finite element models. The algorithmic implementation uses the Bathe (1971) approach, which is known as the Subspace Iteration Method. The modal analysis presented herein, was conducted in order to investigate in-depth the effect of the different retrofitting configurations presented above and establish a better understanding of the overall mechanical behavior of each retrofitted frame (compared to the behavior of the bare frame).

In order to check the obtained values of the newly developed algorithm, the New Greek Seismic Code (NEAK 2000) formula for computing the fundamental period along a certain direction was used, given that it takes into account a more realistic approach compared to both Eurocode 8 (2003) and ACI-318 (2014) codes. Additionally, this choice was made given that the New Greek Seismic Code formula, shown in Eq. 11, accounts for the presence of shear walls and the dimensions of the structure.

$$
T_{1, N E A K}=0.09 \cdot \frac{H}{\sqrt{L}} \sqrt{\frac{H}{H+\rho L}}
$$

where $H$ is the total height of the building, $L$ is the dimension of the building along the direction that the period is computed for, and $\rho$ is the percentage of the summation of the shear wall areas positioned along the direction of the computed oscillation over the total area of the vertical structural members. Based on the NEAK 2000 formula the fundamental period of the bare frame along the $x$-axis is equal to 0.362 seconds $(\rho=0)$, while the corresponding fundamental period of the fully retrofitted frame (infill RC walls throughout the building's height; $\rho=0.7838$ ) is equal to 0.288 seconds (also along the $\mathrm{X}$-axis direction).

Fig. 41 shows the first three eigenshapes and their corresponding eigenmode values as they resulted from the four numerical models that were examined in this research work. As it can be seen, the first mode corresponds always to an out-of-plane translational deformation, which is explained by the fact that the stiffness of the structure in the out-of-plane direction (y-axis) is always smaller than the one computed along the in-plane direction (x-axis). Additionally, the values of all the computed $1^{\text {st }}$ fundamental periods are between 0.39-0.44 seconds, a numerical phenomenon attributed to the similar out-of-plane stiffness of all four models (the infill RC walls are placed along the $\mathrm{x}$-axis thus the stiffness along the y-axis direction is not affected considerably from the interventions). It is also important to note at this point that, the NEAK 2000 formula derives a fundamental period equal to 0.441 seconds for the $y$-axis direction $(\mathrm{H}=12 \mathrm{~m}, \mathrm{~L}=6 \mathrm{~m}, \rho=0)$, which constitutes a $0.22 \%$ accuracy of the numerical analysis (see Fig. 41a).

The corresponding $2^{\text {nd }}$ fundamental period of the bare frame was an in-plane oscillation along the $\mathrm{x}$-axis and the corresponding computed value was found to be 0.37 seconds that is $2.2 \%$ larger than the corresponding value predicted by NEAK 2000. It is also easy to observe that, the $2^{\text {nd }}$ fundamental period decreases as the infill $\mathrm{RC}$ walls increase in height within the different retrofitting configurations (see Figs. 41b, 41c and 41d). This mechanical response was expected in this case given that the taller the infill RC walls get within the South and North frames, the stiffer the building's overall mechanical behavior becomes, thus the corresponding $2^{\text {nd }}$ fundamental period decreases accordingly. Furthermore, it is important to note that the $2^{\text {nd }}$ eigenmode for the one- and two-storey infill RC walls, and the fully retrofitted models derived an overall period duration decrease of $15 \%, 34 \%$ and $48 \%$, respectively, compared to the bare frame. In addition to that, it is also easy to observe the significant difference in terms of horizontal deformations between the bare and the retrofitted floors (see Figs. $41 \mathrm{~b}$ and $41 \mathrm{c}$ ) for the case of the $2^{\text {nd }}$ eigenmode. It is evident that the floors without retrofitting within these models (Figs. 41b and 41c) exhibit larger deformations in comparison to the retrofitted floors. This mechanical behavior is attributed to the significant increase of floor stiffness that converts the framing system into an irregular one, which as a consequence affects the dynamic response of the framing system. 


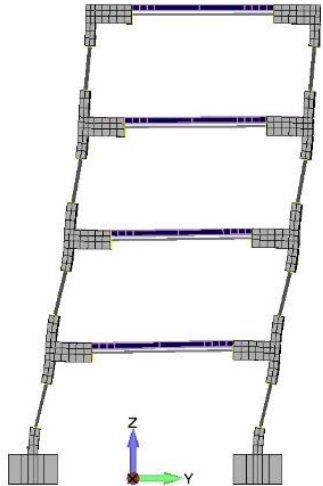

$f_{l}=2.28 \mathrm{~Hz}, \mathrm{~T}_{1}=0.44 \mathrm{~s}$

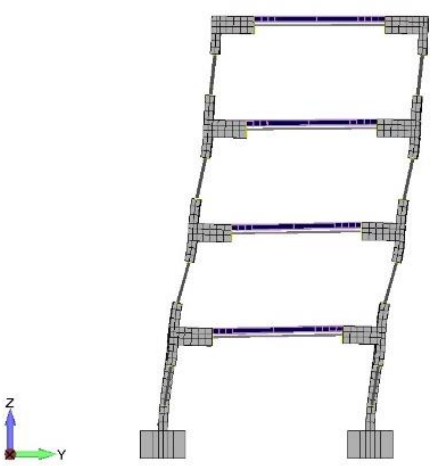

$f_{l}=2.38 \mathrm{~Hz}, \mathrm{~T}_{1}=0.42 \mathrm{~s}$

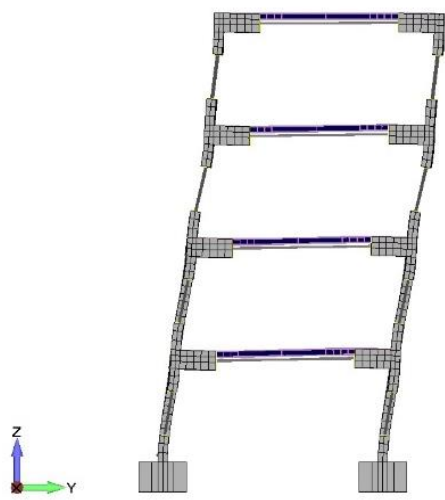

$f_{l}=2.54 \mathrm{~Hz}, \mathrm{~T}_{1}=0.39 \mathrm{~s}$

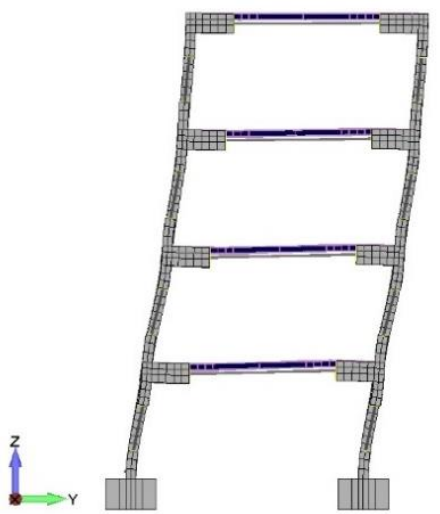

$f_{1}=2.59 \mathrm{~Hz}, \mathrm{~T}_{1}=0.39 \mathrm{~s}$

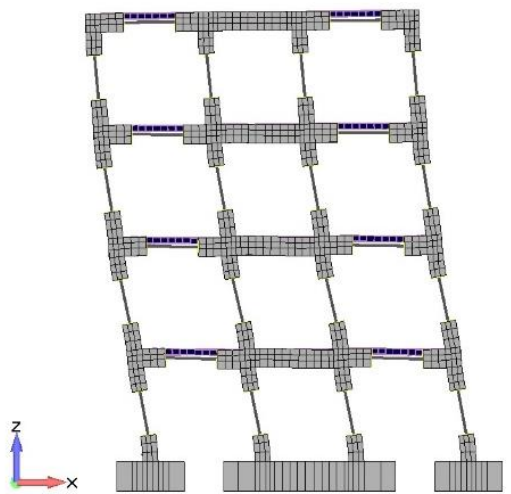

(a) Bare Frame

$f_{2}=2.74 \mathrm{~Hz}, \mathrm{~T}_{2}=0.37 \mathrm{~s}$

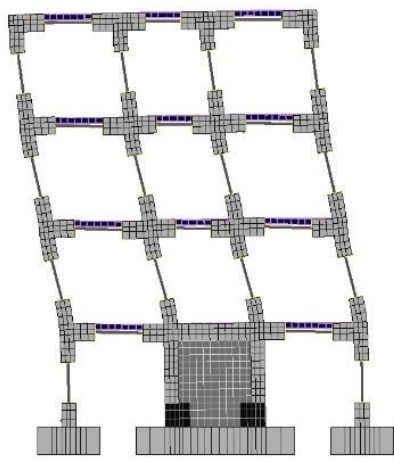

(b) RC Model with One-storey Infill Walls $f_{2}=3.23 \mathrm{~Hz}, \mathrm{~T}_{2}=0.31 \mathrm{~s}$

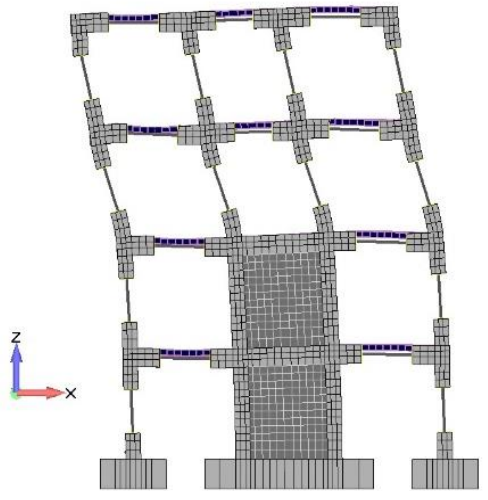

(c) RC Model with Two-storey Infill Walls $f_{2}=4.16 \mathrm{~Hz}, \mathrm{~T}_{2}=0.24 \mathrm{~s}$

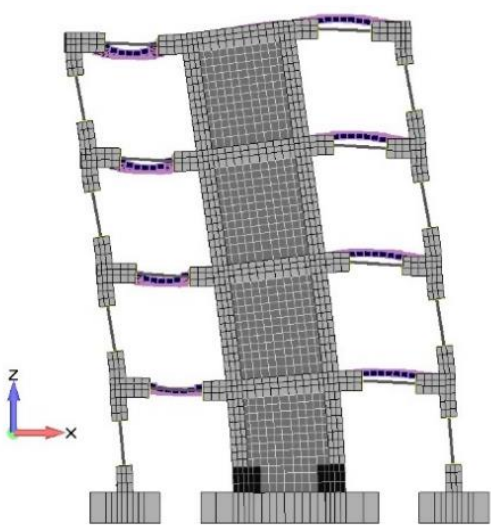

(d) RC Model with Two-storey Infill Walls $f_{2}=5.28 \mathrm{~Hz}, \mathrm{~T}_{2}=0.19 \mathrm{~s}$

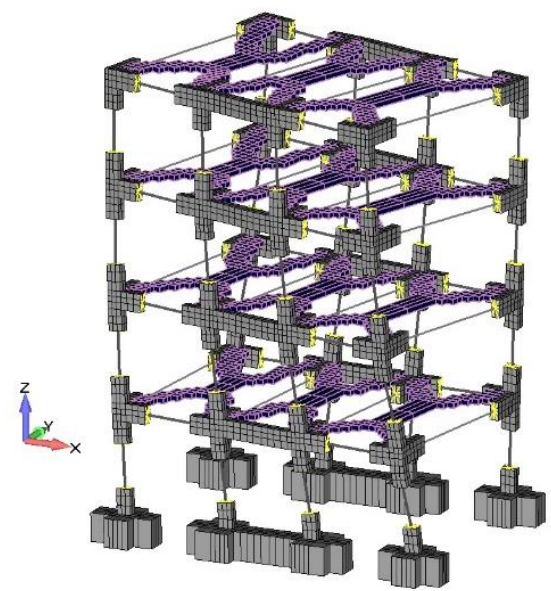

$f_{3}=6.30 \mathrm{~Hz}, \mathrm{~T}_{3}=0.16 \mathrm{~s}$

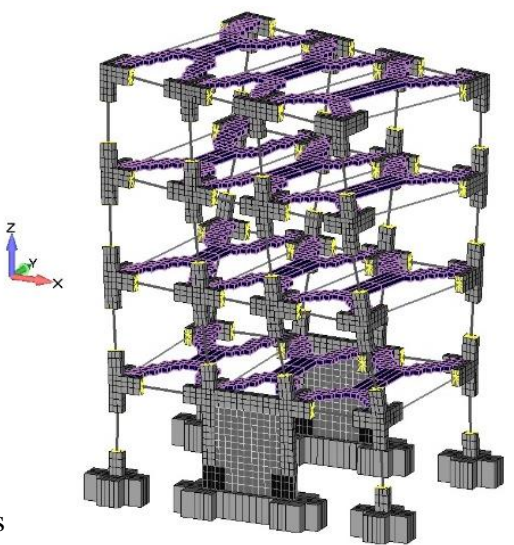

$f_{3}=6.36 \mathrm{~Hz}, \mathrm{~T}_{3}=0.16 \mathrm{~s}$

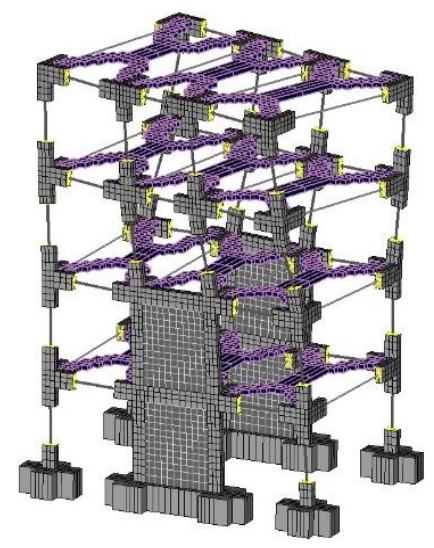

$f_{3}=6.50 \mathrm{~Hz}, \mathrm{~T}_{3}=0.15 \mathrm{~s}$

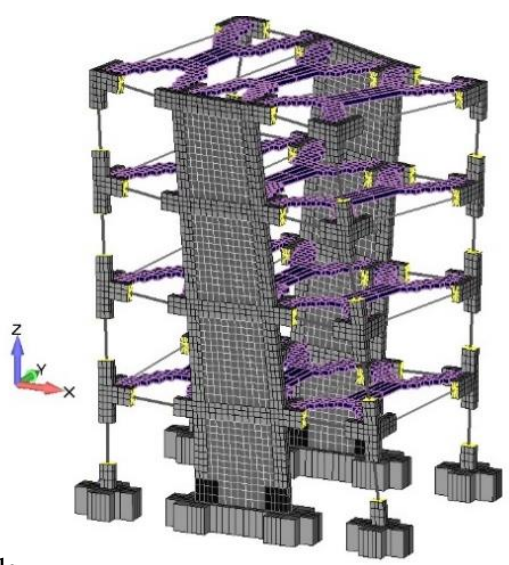

$f_{3}=7.37 \mathrm{~Hz}, \mathrm{~T}_{3}=0.14 \mathrm{~s}$

Fig. 41. Views of the eigenmodes of the 4-storey building with different retrofitting configurations. 
Finally, the $3^{\text {rd }}$ eigenmode that derived though the use of all numerical models was found to be a rotational deformation about the z-axis with the last model (fully retrofitted frame shown in Fig. 41d) exhibiting the stiffest response with a $12.5 \%$ increase in terms of rotational stiffness compared to the bare frame. This numerical finding is connected to the placement of the infill RC walls at all four levels of the frame, which affected the corresponding overall rotational stiffness of the building.

It is evident that, the modal analysis performed and discussed in this section illustrates the importance of selecting not only the proper retrofitting method when strengthening RC structures, but also investigate the effects that the selected geometry of the applied intervention can have on the overall mechanical behavior of the retrofitted framing system. Hence, according to the parametric investigation performed herein, it is strongly advisable to apply infill $\mathrm{RC}$ walls throughout the height of the structure (whenever this is architecturally feasible), while always perform full-scale analyses in allocating the weak areas of the retrofitted structure in the case where the designer foresees the use of infill RC walls at specific floors of the frame and not throughout its height.

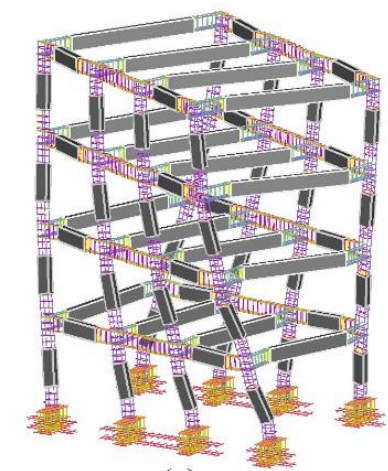

(a)

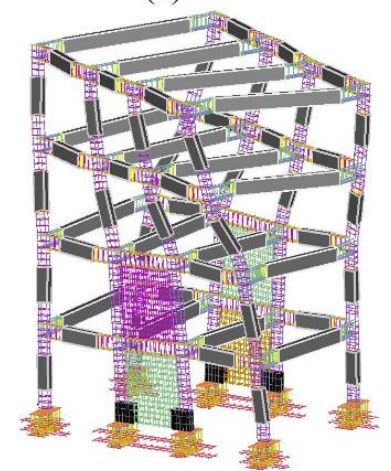

(c)

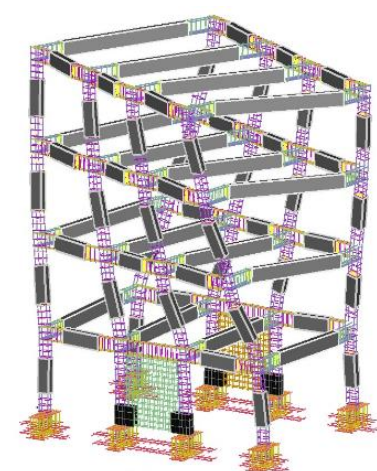

(b)

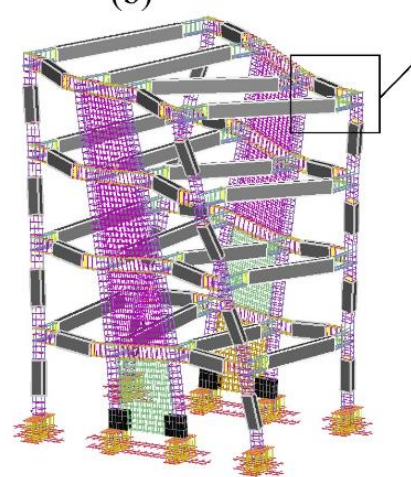

(d)

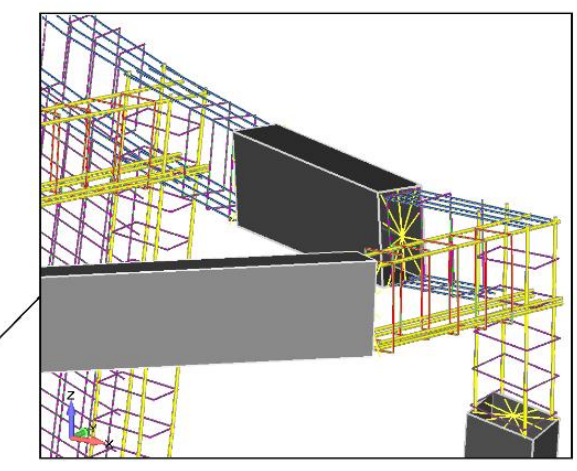

Fig. 42. 3D views of the $3^{\text {rd }}$ eigenmode of the models with (a) a bare frame, (b) one-storey infill RC walls, (c) two-storey infill RC walls and (d) fully retrofitted frame. Embedded rebar elements deformed views.

In order to further verify the developed algorithm that was used to perform the modal analysis, the deformed shape of the embedded rebar elements was visualized for all the derived eigenmodes. Fig. 42 shows the deformed shapes of the $3^{\text {rd }}$ eigenshape for each model as they resulted from the modal analyses. In the illustrated views of Fig. 42, the slabs and all concrete hexahedral elements were deactivated from the model's view so as to reveal the deformed shape of the embedded rebar elements that were found in all cases to follow the deformed shape of the concrete domain. Finally, Table 10 shows the computational time for the solution stage of the modal analysis that were performed by using the four under study finite element HYMOD models (the requested number of modes was set to 12). As it can be seen, the required computational time to solve the modal analysis problem was between 30-37 seconds, which demonstrates the computational efficiency of the developed algorithm. The total required computational time, when computing and writing the results of the 12 first eigenmodes, including output file writing, was not more than 3 minutes for all numerical models.

To further investigate the algorithmic performance of the modal analysis implementation, two additional runs were performed through the use of the bare and fully retrofitted frame models in an attempt to compute the first 200 eigenmodes of the two framing systems. As it can be seen in Table 10, the corresponding modal analysis solution time was 170 and 233 seconds, respectively, which approximately corresponds to an overall average of 1 second per eigenmode. It must be noted here 
that, the writing procedure foresees the writing of the computed displacements for each node and the stresses and strains of each finite element's Gauss point. This makes the writing procedure of the output file time consuming, where more than $80 \%$ of the total computational time is dedicated to I/O processes (this applies for the case when the requested number of eigenmodes was set to 200). By deactivating the writing of stresses and strains, the I/O time can be decreased significantly (approximately by 90\%), thus make this process more computationally efficient.

Table 10 Computational performance of the Modal Analysis Algorithm. Computing 12 eigenmodes.

\begin{tabular}{|c|l|c|c|c|c|c|}
\hline a/a & \multicolumn{1}{|c|}{ Model } & $\begin{array}{c}\text { Number of } \\
\text { Hexa } \\
\text { Elements }\end{array}$ & $\begin{array}{c}\text { Number of } \\
\text { Embedded } \\
\text { Rebar Elements }\end{array}$ & $\begin{array}{c}\text { Total Number of } \\
\text { Degrees of } \\
\text { Freedom }\end{array}$ & $\begin{array}{c}\text { Modal Analysis } \\
\text { Solution Time } \\
(\mathrm{s})\end{array}$ & $\begin{array}{c}\text { Total Comp. } \\
\text { Time } \\
(\mathrm{m})\end{array}$ \\
\hline 1 & Bare Frame & 5,500 & 14,546 & 32,028 & 30 & 1.82 \\
\hline 2 & Retrofitted 1 & 6,136 & 15,462 & 34,416 & 30 & 1.92 \\
\hline 3 & Retrofitted 2 & 6,868 & 17,162 & 37,764 & 31 & 2.13 \\
\hline 4 & Fully Retrofitted & 8,356 & 20,646 & 43,896 & 37 & 2.68 \\
\hline 5 & Bare Frame & 5,500 & 14,546 & 32,028 & $170^{*}$ & $19.08^{*}$ \\
\hline 6 & Fully Retrofitted & 8,356 & 20,646 & 43,896 & $233^{*}$ & $27.65^{*}$ \\
\hline
\end{tabular}

*Computing 200 eigenmodes.

\section{Conclusions and Future Work}

A complete numerical investigation was performed and presented in this research work, which dealt with the full-scale nonlinear cyclic modeling of a 4-storey RC building that was retrofitted with RC infill walls and CFRP jacketing. The experimental setup that foresaw the application of three consecutive loading histories was modeled and analyzed through the use of the HYMOD approach (Markou et al. 2018), which foresees the use of a 3D detailed FE mesh discretization of the sheardominated parts of the structure, where the rest of the structural members are modeled through the computationally efficient NBCFB element.

Based on the numerical investigation that was presented herein, the developed proposed modeling approach managed to overcome the computational limitations when dealing with this type of problems, simulating the entire 4-storey RC building for all loading tests based on the experimental data (3 cyclic loading history tests) without any numerical problems. Furthermore, the proposed modeling approach did not foresee for any simplification assumptions, thus the geometry of the entire building, its retrofitting domains and the steel reinforcement were modeled in an exact manner, while the material properties that were defined during the model construction complied with the values reported in the experimental report. This highlights the practicality, numerical simplicity and objectivity of the proposed modeling approach, when dealing with the assessment of RC retrofitted structures by using cyclic nonlinear ultimate limit state analysis.

The numerical investigation also revealed that the proposed modeling method managed to capture accurately the experimental results (Martin et al. 2013) that were obtained during the three consecutive loading tests, while maintaining a low ratio of internal iterations per displacement increment. Based on the numerical findings, the main strain concentrations and damages on the frame were found to be located at the structure's joints and RC shear walls; a numerical finding that complied with the experimental results reported in Martin et al. (2013). The building's numerically obtained mechanical behavior is mainly attributed to the large shear strains that occurred at these areas of the frame during the cyclic analysis (shear-dominated areas).

The CFRP jacketing that was discretized and incorporated within the HYMOD mesh, was found to affect the stress-strain distribution at a local level, therefore, taking into account the confinement due to this retrofitting technique during the nonlinear cyclic analysis was found to be important when numerically investigating the mechanical response of the retrofitted frame. It must be further stressed out here that, the material properties used for the simulation of all cyclic loading tests presented in this research work, were the same throughout the numerical analyses, while all the material property values were equal to the material properties reported in Martin et al. (2013). This numerical advantage minimized the required number of models used during the numerical investigation to just a single mesh that was adopted in performing all analyses. Furthermore, a final analysis was performed and presented in section 5.4 for the case of a model that was developed by modifying the material property magnitudes of both steel and concrete materials (hardening modulus and tensile strength, 
respectively). This was done in order to investigate the numerical performance of the adopted modeling approach when indirectly accounting for the accumulated material damage due to consecutive cyclic loading excitations. The numerically obtained results showed that the hardening modulus of steel was the parameter that controlled the overall resistance of the framing system due to the high nonlinearities that were developed during the $3^{\text {rd }}$ and final loading test. This numerical phenomenon highlights the importance of the material property magnitudes that have to be defined during the development of a FE model that is intended to be used for the assessment of a damaged or retrofitted RC building. For this reason, the need of objective numerical models that require the minimum number of material and modeling assumptions is imperative, especially when dealing with full-scale RC structural seismic assessment analyses.

After the model validation and the in-depth retrofitted frame analysis were successfully completed, the HYMOD model was used to perform a numerical investigation of different infill RC wall retrofitting configurations. The initial HYMOD mesh was used to construct three new models by removing the infill $\mathrm{RC}$ wall elements accordingly. Based on the numerical findings presented in section 5.5, it was concluded that the model, which foresaw the use of infill RC walls throughout the height of the structure, derived the highest shear capacity and energy dissipation enhancements. Its overall energy dissipation due to the infill $\mathrm{RC}$ walls was found to increase by $500 \%$ in comparison to the bare frame model. Additionally, it was concluded that there could be cases where the placing of more infill $\mathrm{RC}$ walls during the strengthening design procedure of a $\mathrm{RC}$ frame, will not always translate into a proportional enhancement of the overall shear capacity and energy dissipation. The numerical investigation revealed that local damage accumulation could result into a premature failure of the structure due to excessive damage concentrations at the structural members found at higher floors that were not retrofitted. Therefore, full-scale nonlinear analyses should be performed so as to allocate potential weak areas of the framing system, thus establish an optimum and cost-effective retrofitting design.

Furthermore, Reconan FEA was integrated with a modal analysis algorithm that was used to compute the eigenmodes and their corresponding values by using the four finite element meshes presented in section 5.5. The use of HYMOD meshes in modal analysis was presented here for the first time in the international literature. Based on the modal analysis findings, it was concluded that the two models that were not retrofitted by using infill walls throughout the frame's height, incorporated an irregular stiffness distribution along their height that translated into an irregular deformation between their retrofitted and bare floors. Based on this finding, it is advisable to avoid placing infill RC walls that will not cover the full height of the structure (whenever this is architecturally feasible). In addition to the presented parametric investigation in regards to the four HYMOD models, the computational efficiency of the developed modal analysis algorithm and its numerical validation, were performed and discussed in section 5.5. The obtained numerical response of the developed modal analysis algorithm was found to be computationally efficient and numerically accurate.

The overall numerical response of the developed algorithm, in terms of its ability to capture the cyclic behavior of RC structures that have undergone consecutive cyclic excitations, was found to be satisfactory. Therefore, modeling and analyzing full-scale structures with 3D detailed models is now feasible, thus the proposed modeling method provides with the required tools to perform additional numerical investigations for the study of different retrofitting techniques in developing optimum retrofitting design recommendations. This will be the main objective of a future research project.

In addition, a second future objective of this research work is to integrate the HYMOD algorithm with realistic material damage factors for concrete and steel that will provide with the ability to capture the pinching effect. Currently, a research project that deals with unreduced models is being successfully finalized and the numerical findings will be presented in a forthcoming publication. Finally, HYMOD will be integrated with a dynamic solver in order to be used in analyzing full-scale RC multi-storey buildings under nonlinear dynamic loading conditions. Having the ability to analyze the effectiveness and efficiency of retrofitted framing systems through 3D detailed dynamic analysis, will provide with the required numerical tools in developing a deep understanding on the mechanical response of this type of framing systems. 


\section{Acknowledgement}

The authors would like to acknowledge the financial support provided by the European Research Council Advanced Grant "MASTER-Mastering the computational challenges in numerical modeling and optimum design of CNT reinforced composites" (ERC-2011-ADG 20110209). They would also like to acknowledge Martin Poljansek for providing with the experimental data that were used in this research work.

\section{References}

ACI318-14, Building Code Requirements for Structural Concrete and Commentary, ACI Committee 318, 2014. Bark, H., Markou, G., Mourlas, Ch. and Papadrakakis, M., "Seismic Assessment of a 5-Storey Retrofitted RC Building", ECCOMAS Congress, VII European Congress on Computational Methods in Applied Sciences and Engineering, Crete Island, Greece, 5-10 June 2016.

Bathe, K.J., Solution Methods for Large Generalized Eigenvalue Problems in Structural Engineering, Report UCSESM 71-20, Department of Civil Engineering, University of California, Berkeley, 1971.

Blanco, P.J., Feijoo, R.A. and Urquiza, S.A. (2007), "A unified variational approach for coupling 3D-1D models and its blood flow applications", Comput. Methods Appl. Mech. Engrg., Vol. 196, 4391:4410.

Blanco, P.J., Feijoo, R.A. and Urquiza, S.A. (2008), "A variational approach for coupling kinematically incompatible structural models", Comput. Methods Appl. Mech. Engrg., Vol. 197, 1577:1602.

Bournival, S., Cuillière, J.-C. and François, V. (2010), "A mesh-based method for coupling 1D and 3D elements." Advances in Engineering Software, Vol. 41, 838:858.

Červenka J. and Papanikolaou V.K. (2008), "Three dimensional combined fracture-plastic material model for concrete, International Journal of Plasticity", 24(12), 2192-2220.

Eurocode 8 (2003), Design of structures for earthquake resistance.

Formaggia, L., Gerbeau, J.F., Nobile, F. and Quarteroni, A. (2001), "On the coupling of 3D and 1D NavierStokes equations for flow problems in compliant vessels", Comput. Methods Appl. Mech. Engrg., Vol. 191, 561:582.

Gonzalez-Vidosa F., Kotsovos M.D. and Pavlovic M.N. (1991), "A three-dimensional nonlinear finite-element model for structural concrete. Part 1: main features and objectivity study; and Part 2: generality study", Proceedings of the Institution of Civil Engineers, Part 2, Research and Theory, Vol. 91, 517-544.

Hartl, H. (2002), "Development of a continuum mechanics based tool for 3D FEA of RC Structures and application to problems of soil structure interaction." Ph.D. thesis, Faculty of Civil Engineering, Graz Univ. of Technology.

Huang J. (2004), "Numerical solution of the elastic body-plate problem by nonoverlapping domain decomposition type techniques", Math. Comput., Vol. 73, 19:34.

KANEPE (2012). Code for Intervention in Reinforced Concrete Buildings, Earthquake Planning and Protection Organization (OASP).

Kozlov, V.A. and Maz'ya, V.A. (2001), "Fields in non-degenerate 1D-3D elastic multi-structures", Quart. J. Mech. Appl. Math., Vol. 54, 177:212.

Kyriakides, N., Chrysostomou, Ch. Z., Kotronis, P., Georgiou, E. and Roussis, P. (2015), "Numerical simulation of the experimental results of a RC frame retrofitted with RC Infill walls", Earthquakes and Structures, vol. 9 (4).

Lykidis, G.Ch. and Spiliopoulos K.V. (2008), “3D solid finite element analysis of cyclically loaded RC structures allowing embedded reinforcement slippage", Journal of Structural Engineering-ASCE, 134(4), 629-638.

Markou G. and Papadrakakis M. (2013), "Computationally efficient 3D finite element modeling of RC structures. Computers and Concrete", 12(4), 443-98.

Markou G. and AlHamaydeh M. (2017), "3D Finite Element Modeling of GFRP-Reinforced Concrete Deep Beams without Shear Reinforcement", International Journal of Computational Methods, International Journal of Computational Methods, 15(1), 1-35.

Markou G. and Papadrakakis M. (2015), “A Simplified and Efficient Hybrid Finite Element Model (HYMOD) for Non-Linear 3D Simulation of RC Structures", Engineering Computations, Vol. 32 (5), 1477-1524.

Markou G., Mourlas Ch. and Papadrakakis M. (2017), Cyclic Nonlinear Analysis of Large-Scale Finite Element Meshes Through the Use of Hybrid Modeling (HYMOD), International Journal of Mechanics, 11(2017), 218-225.

Markou G., Mourlas Ch. and Papadrakakis M. (2018), "A hybrid finite element model (HYMOD) for the nonlinear 3D cyclic simulation of RC structures”, International Journal of Computational Methods, 15(5), 1-40. 
Martin P., Fabio T., Javier M. R., Christis Ch., Nicholas K., Toula O., Panayiotis R., Panagiotis K., Telemachos P., Antonis K. (2013), Seismic Retrofitting of RC Frames with RC Infilling (SERFIN Project), European Commission, Joint Research Center, Institute of the Protection and Security of Citizens.

Mata, P., Barbat, A.H. and Oller, S. (2008), "Two-scale approach for the nonlinear dynamic analysis of RC structures with local non-prismatic parts", Vol. 30(12), 3667:3680.

Menegotto, M., and Pinto, P. E. (1973). "Method of analysis for cyclically loaded reinforced concrete plane frames including changes in geometry and non-elastic behavior of elements under combined normal force and bending." Proceedings, IABSE Symposium on Resistance and Ultimate Deformability of Structures Acted on by Well Defined Repeated Loads, Lisbon, Portugal, 15-22.

Mourlas Ch., Papadrakakis M. and Markou G. (2017), "A computationally efficient model for the cyclic behavior of reinforced concrete structural members", Engineering Structures. Vol. 141, 97-125.

Nazarov, S.A. (1996), "Junctions of singularly degenerating domains with different limit dimensions I", J. Math. Sci., Vol. 80, 1989:2034.

Nazarov, S.A. (1999), "Junctions of singularly degenerating domains with different limit dimensions II", J. Math. Sci. Vol. 97, 4085:4108.

New Greek Seismic Code (NEAK), Athens, 2000.

Papanikolaou V.K. and Kappos A.J. (2009), "Numerical study of confinement effectiveness in solid and hollow reinforced concrete bridge piers: Part 1: Methodology and Part 2: Analysis results and discussion. Engineering Structures", Vol. 87, 1427-1439, 1440-1450, 2009.

Rashid Y.M. (1968), Ultimate strength analysis of prestressed concrete vessels, Nucl Eng and Des, Vol. 7, 334344.

Urquiza, S.A., Blanco, P.J., Venere, M.J. and Feijoo, R.A. (2006), "Multidimensional modelling for the carotid artery blood flow", Comput. Methods Appl. Mech. Engrg., Vol. 195, 4002:4017.

Willam K. J. and Warnke E. P., (1974), "Constitutive model for the triaxial behaviour of concrete", Seminar on concrete structures subjected to triaxial stresses, Instituto Sperimentale Modeli e Strutture, Bergamo, Paper III-1. 